\title{
The Unfolding Story of the Second Demographic Transition
}

\author{
RON LESTHAEgHE
}

THE DEMOGRAPHIC TRANSITION refers to the declines in fertility and mortality that occurred in Western countries from the eighteenth and nineteenth centuries onward and during the second half of the twentieth century in much of the rest of the world. At present, there are barely a dozen countries that have not begun a fertility decline. In the West, the control of fertility within wedlock occurred in tandem with a reduction in celibacy and a lowering of ages at marriage, signaling a major departure from its Malthusian marriage system. In the rest of the world, early marriage for women-often the result of arrangements between families or lineages-gave way to much later marriage, partly because of more individual partner choice and partly as a response to economic factors. On the whole, William Goode's prediction of 1963 forecasting a rise in non-Western ages at marriage has largely been borne out by the record of the last 40 years. This increase in ages at marriage has furthermore been a major component in the overall fertility decline in many non-Western countries.

But even before the demographic transition started spreading from the West and Japan to the less developed countries, Western populations were initiating a process that would take them far beyond what postwar demographic transition theory had forecasted. ${ }^{1}$ The fertility decline did not stop at around two children on average, and Western marriage would not stay early or attract the vast majority of men and women. The end product does not seem to be a balanced stationary population with zero population growth and little or no need for immigrants. This "second demographic transition" (SDT) brings sustained sub-replacement fertility, a multitude of living arrangements other than marriage, the disconnection between marriage and procreation, and no stationary population. Instead, Western populations face declining sizes, and if it were not for immigration, that decline would already have started in many European countries. In addition, continued gains in longevity at older ages in tandem with sustained sub-replacement fertility will lead 
to additional population aging. This aging cannot be fully compensated by "replacement migration."

The early signs of the second demographic transition emerged in the 1950s: divorce rates were rising, especially in the United States and Scandinavia, and the departure from a life-long commitment was justified by the logic that "a good divorce is better than a bad marriage." From the second half of the 1960s onward, fertility started falling from its "baby boom" high. Moreover, the trend in ages at first marriage was reversed again, and proportions single started rising. Soon thereafter, it became evident that premarital cohabitation was on the rise and that divorce and widowhood were followed less frequently by remarriage and more often by postmarital cohabitation. By the 1980s even procreation within cohabiting unions had spread from Scandinavia to the rest of Western Europe. In both France and the United Kingdom, more than 40 percent of all births now occur out of wedlock. In 1960 the figure for both countries was 6 percent.

The notion of a second demographic transition, which Dirk van de Kaa and I introduced in 1986 in a short article in the Dutch sociology journal Mens en Maatschappij, has been criticized from different perspectives. ${ }^{2}$ First, it was maintained that the SDT would merely be the continuation of the one and only transition (e.g., Cliquet 1992). Second, according to David Coleman (2004, p. 11), it would not be a "second transition," but merely a "secondary feature" of the demographic transition. The second demographic transition would, according to Coleman, not even be demographic in nature, but only a "partial analysis of life style preferences." Third, a more common argument, particularly in the 1990s, has been that the SDT is an archetypical Western European (plus Canadian and Australian) feature that would not spread to the United States or to Southern, Central, and Eastern Europe, let alone Asia. Instead, the demographic changes in the latter parts of Europe could be accounted for by the economic turmoil associated with the transition from Communist to market economies, without involving the operation of a cultural shift. In the United States, widely held Christian values would stem the tide and strengthen American "exceptionalism," as for instance exhibited by the absence of sub-replacement fertility. Fourth, it was suggested that the theory of the SDT overemphasized the link between the transformation in family relationships (especially cohabitation) and the prevalence of sub-replacement fertility. In other words, the family formation variables associated with the SDT would not be as cohesive as envisaged in 1986. Fifth, the SDT theory could not account for the great variety of fertility levels from barely below replacement to "lowest low." Finally, questions inevitably arose about the universality of the SDT: could its features spread to Asia and other continents as societies grew richer, or is the SDT a Western idiosyncrasy and bound to remain so?

These questions set the agenda for the following analysis. 


\section{Is the second demographic transition merely the continuation of the first?}

The idea of the distinctness of the SDT stems from Philippe Ariès's analysis of the history of childhood (1962) and, as van de Kaa and I have repeatedly pointed out, from his 1980 article on the two successive and distinct motivations for parenthood. During the first demographic transition, the decline in fertility was "unleashed by an enormous sentimental and financial investment in the child" (i.e., the "king child era," to use Ariès's term) (Ariès 1980, p. 649), whereas the motivation during the second transition is adult self-realization within the role or life style as a parent or more complete and fulfilled adult. This major shift is also propped up by the innovation of hormonal and other forms of highly efficient contraception. During the first transition couples chose to adopt contraception in order to avoid pregnancies; during the second, the basic decision is to stop contraception in order to start a pregnancy.

The other "root" of the SDT theory was connected to a reaction of van de Kaa and myself toward the cyclical fertility theory, as formulated by Richard Easterlin (1973). In this theory, small cohorts would have better employment opportunities and hence earlier marriage and higher fertility, whereas large cohorts would have the opposite life chances and inverse demographic responses. Easterlin's theory accounts well for the marriage boom and baby boom of the 1960s, and also for the subsequent baby bust of the 1970s. But the theory equally predicts further cycles produced by the earlier ones, and hence expects a return of fertility to higher levels when smaller cohorts reach the reproductive years. By the middle of the 1980s van de Kaa and I had become convinced that sub-replacement fertility was not only going to last much longer, but could even become an "intrinsic" feature of a new demographic regime. Thus, we saw the discrediting of the model of an ultimate stationary population with a long-term population equilibrium, and of the revised version of the model that postulated cyclical fertility swings around replacement fertility.

But there was more behind the idea of the second demographic transition than these two considerations. Further in the background was the concept of a Maslowian preference drift. Stated succinctly, Abraham Maslow (and others before him) noticed that greater economic development produced a shift in concerns about material needs (subsistence, shelter, physical and economic security) to a focus on non-material needs (freedom of expression, participation and emancipation, self-realization and autonomy, recognition). With such a shift in needs, a shift in the values structure would also occur, with tolerance for diversity and respect for individual choices gradually taking over as prime values from solidarity and social group adherence and cohesion. With this background in mind, the first demographic transition is considered as anchored mainly in the stage of the realization of basic material needs, 
whereas the second demographic transition is the expression of the development of higher-order, non-material needs and of expressive values.

Also note that the explicit inclusion of the Maslowian drift sets the SDT theory apart from both the neoclassic economic interpretation and any neoMarxist or purely structural sociology and history. The latter see demographic change merely as a response to changes in material circumstance and either fail to incorporate cultural shifts altogether or fail to specify universal mechanisms that link material to non-material driving forces. At this point one will notice the close resemblance of the SDT theory to the theory developed by Ron Inglehart in the field of political science (e.g., Inglehart 1970, 1997).

Having pointed out the intellectual origins of the SDT, I now offer a more systematic treatment of the contrasts between the first and second demographic transitions. Appendix Table 1 summarizes the points discussed below.

\section{Contrasting nuptiality regimes}

As I indicated earlier, a first major contrast between the first and second transitions is their trends in nuptiality. In Western Europe the Malthusian pattern of late marriage weakened, mainly because of the growth of wageearning labor, and this basic trend toward earlier and more universal marriage continued until the mid-1960s. Hence, the lowest mean ages at first marriage since the Renaissance were reached in the middle of the twentieth century. Furthermore, the pockets of Western Europe where cohabitation and outof-wedlock fertility had remained high during the nineteenth century were under siege during the first half of the twentieth. Such behavior was not in line with the religious and secular views on what constituted a proper family. Extramarital fertility rates declined throughout Europe after 1900.

By contrast, after 1965, ages at marriage rose again and cohort proportions ever-married started declining (Council of Europe 2004). This resulted not only from an interim period of premarital cohabitation, but also from later home leaving and more and longer single living. The very rapid prolongation of education for both sexes since the 1950s and the ensuing change in the educational composition of Western populations contributed to this process. But the unfolding of the nuptiality features of the SDT did not stop at a rise in ages at marriage and at a mere insertion of an interim "student" period. Postmarital cohabitation too was on the rise, as was childbearing outside wedlock. And in many instances the latter trend is to some extent a "revenge of history": cohabitation and procreation by non-married couples are now often highest where the custom prevailed longest during the nineteenth and early twentieth centuries. ${ }^{3}$

Another contrast between the first and second transitions pertains to divorce and remarriage. The first transition was preoccupied with strengthen- 
ing marriage and the family, and divorce legislation remained strict. The state offered little opposition to religious doctrine in this respect. Divorce on the basis of mutual consent was rare and mostly based on proven adultery. The second transition witnessed the end of a long period of low divorce rates, and the principle of a unique, life-long legal partnership was questioned. This took the form of a rational "utility" evaluation of marriage in terms of the welfare of both adult partners first and children second. This questioning was accompanied by attacks on the hypocrisy of the earlier restrictive divorce legislation that fostered concubinage instead. The outcome in Western Europe, the United States, Canada, Australia, and New Zealand was a succession of legal liberalizations in the wake of a singularly rising demographic trend. And, as pointed out in the introduction, the onset of the rise in divorce was probably the very first manifestation of the accentuation of individual autonomy in opposing the moral order prescribed by Church and State. It should be noted, however, that resistance to divorce was stronger in countries or regions with a Catholic background than in those with a Protestant heritage. This is not so surprising since divorce versus the indissolubility of marriage was one of the key issues that led to the Reformation in the first place.

And last but not least, the first and second transitions have opposite patterns of remarriage. During the first, remarriages essentially involved widows and widowers, whereas remarriage for divorced persons meant a new beginning and the start of a new family: new children for a new lifelong commitment. In other words, even if divorce occurred, the institution of marriage was not under serious threat, and remarriage propped up fertility as well. Nothing of this is left in the second transition: remarriages among the widowed or divorced decline in favor of cohabitation or other looser arrangements such as LAT ("living apart together") relationships or intimate friendships.

\section{Fertility contrasts}

The theory of the second demographic transition does not merely focus on changing nuptiality and family patterns, as Coleman contends, but is equally concerned with fertility. Recall that Ariès's essay on two successive fertility motivations and Easterlin's work on a cyclical fertility model were two intellectual foundations of the theory. Even if that were not the case, fertility cannot be studied without regard to the fundamental changes in patterns of household formation and without the framework of changing life style preferences.

During the first transition, fertility was increasingly confined to marriage, contraception affected mostly fertility at older ages, mean ages at first parenthood declined, and childlessness among married couples was low. There are examples of below-replacement fertility during the first transition, 
but these correspond to exceptional periods of economic crisis or war. Subreplacement fertility is not an intrinsic characteristic of the first transition. Under more favorable conditions, as for instance after World War II, fertility levels are well above replacement level, and this holds not only for period fertility indicators but also for cohort fertility. The baby boom and the marriage boom of the late 1950s and early 1960s are the last typical features of the first demographic transition in the industrialized world. Another salient characteristic of the fertility regime during the first transition was its reliance on imperfect contraception. Until the 1960s, withdrawal was largely the method used by the working classes, and rhythm by better-educated or more religious couples. Both methods led to contraceptive failures and unintended pregnancies, and these kept fertility above replacement level. Particularly such contraceptive failures at higher ages became increasingly undesirable and prompted the demand for more effective contraception.

The second demographic transition started with a multifaceted revolution, and all aspects of it affect fertility. First, a contraceptive revolution was heralded by the invention of the pill and the re-invention of IUDs. All of these were perfected very rapidly, and hormonal contraception was particularly suited for postponing and spacing births. Ansley Coale's "learning curve" of contraception, which increased monotonically with age and parity and fitted the first transition experience so well, was no longer applicable in the West. After an interim period with increased incidence of "shotgun marriages" (generally around 1965-75), the use of highly efficient and reliable contraception started at young ages and permitted postponement of childbearing as a goal in its own right. Second, the sexual revolution marked a forceful reaction to the notions that sex is confined to marriage and mainly for procreation only. Younger generations sought the value of sex for its own sake and accused their parents' generation of hypocrisy. Ages at first sexual intercourse declined during the second transition. Third, a gender revolution occurred whereby women were no longer subservient to men and husbands, but asserted the right to regulate their fertility. Women's desire for "biological autonomy" was articulated by subsequent quests for the liberalization of induced abortion. Finally, these three revolutions fit within the framework of a rejection of authority and an overhaul of the normative structure. Parents, educators, churches, army, and much of the entire state apparatus ended up in the dock. This entire ideational reorientation, if not revolution, occurred during the peak years of economic growth and shaped all aspects of the SDT.

The pattern of fertility associated with the second demographic transition is its marked degree of postponement. Mean ages at first parenthood for women in sexual unions rose rapidly and to unprecedented levels in several Western European populations. The net outcome was sub-replacement fertility: without the ethnic component (such as Hispanics in the US or Maoris in New Zealand), all OECD countries have sub-replacement fertility. Admittedly, period measures such as the total fertility rate are depressed as a result 
of continued postponement, but even the end of such postponement would not be likely to bring period fertility back to a TFR of 2.1. Most cohorts of the world's white (and Japanese) national populations born after 1960 will not rebound to that level (cf. Frejka and Calot 2001; Lesthaeghe 2001; Council of Europe 2004). However, the degree of heterogeneity in cohort fertility is substantial and by no means solely the outcome of ethnic composition factors. In the West, Scandinavian, British, and French cohorts born in 1960 still come close to replacement fertility, whereas corresponding cohort levels fall below 1.7 in Austria, Germany, and Italy. In Central and Eastern Europe, the cohort of 1960 will still reach two children on average, but not in the Russian Federation, Slovenia, and the three Baltic countries (Council of Europe 2004). Moreover, in Western and Southern Europe, with current total period fertility rates below 1.5, the catching up of fertility after age 30 has remained too weak to offset the effect of postponement. The result of sustained subreplacement fertility is that another, but originally unanticipated trait of the second demographic transition may be in the making: continued reliance on international migration to partially offset the population decline that would otherwise emerge within a few years.

We are evidently far from the ideal first transition outcome of a new stationary population corresponding to high life expectancy, replacement fertility, and little need for immigration. And we are getting further and further removed from the fertility-enhancing prop of that demographic model- the dominance of a single form of living arrangement for couples and children, namely marriage. Finally, the linchpin of the first transition system has totally eroded: collective behavior is no longer kept in check by a strong normative structure based on a familistic ideology supported by both Church and State. Instead, the new regime is governed by the primacy of individual choice. Or as van de Kaa (2004, p. 77) has put it, fertility is now merely a "derivative," the outcome of a prolonged "process of self-questioning and self-confrontation by prospective parents... [in which] the pair will weigh a great many issues, including direct costs and opportunity costs, but their guiding light will be the outcome of self-confrontation. Would a conception and having a child be self-fulfilling?"

\section{Underlying societal contrasts}

To this point we have discussed the differences between the first and second transitions mainly in terms of their demographic contrasts. But both transitions of course have their roots in distinct historical periods of societal development.

With the exception of the very early eighteenth-century fertility decline in France and a few other smaller areas in Europe, much of the first transition was an integral part of development in which economic growth fostered material aspirations and improvements in living conditions. The preoccupations 
of the period 1860-1960 were mainly concerned with increasing household real income, improving working and housing conditions, raising standards of health and life expectancy, improving human capital by investing in education, and providing a safety net through the gradual construction of a social security system. In Europe, these social goals were shared and promoted by all ideological, religious, or political factions (also known as "pillars" since each of them integrates a political party, a cluster of labor unions, news media, and social services into a closely tied organizational network). And in this endeavor, solidarity was a central concept. All pillars also had their views on the desirable evolution of the family.

For the religious pillars (Catholic, Protestant, and later Christian-Democrat) these views were based on the holiness of matrimony, but their defense of a closely knit conjugal family also stemmed from fears that industrial society would lead to immorality, various social pathologies, and atheism. The secular pillars (Liberal and Socialist) equally saw the family as a first line of defense against the social ills of the nineteenth century, and as the foundation for a new social order based on humanistic principles. Hence, although for partially different reasons, all pillars considered the family as the cornerstone of society. Both material and moral uplifting would furthermore be served best by a sharp gender-based division of labor within the family: husbands assumed their responsibilities as devoted breadwinners, and wives became the caretakers of all matters related to quality of life. For this to be realized, male incomes needed to be high enough so that women could assume the role of housewives. In other words, all pillars, including the Socialist and even the Western European Communist ones during the interbellum, contributed to the embourgeoisement of the working class through this propagation of the breadwinner-housewife model.

In short, all social classes were expected to adhere to a single family model that was buttressed by highly ordered life-course transitions: no marriage without solid financial basis or prospects, and procreation strictly within wedlock. The Malthusian preconditions of a "prudent" marriage were readapted to the social aspirations of the new industrial society.

The second demographic transition, on the other hand, is founded on the rise of the higher-order needs as defined by Maslow (1954). Once the basic material preoccupations, particularly long-term financial security, are satisfied through welfare state provisions, more existential and expressive needs become articulated. These are centered on self-actualization in formulating goals, individual autonomy in choosing means, and recognition by others for their realization. These features emerge in a variety of domains, and this is why the SDT can be linked to a wide variety of empirical indicators of ideational change.

In the political sphere such higher-order or "post-materialist" (Inglehart 1970) needs deal, inter alia, with the quest for more direct, grassroots democ- 
racy, openness of government, rejection of political patronage, decline of life-long loyalty to political or religious pillars, and the rise of ecological and other quality-oriented issues on the political agenda. The negative manifestation is rising distrust in politics and institutions and growing political anomy that can fuel right wing extremism. The state is no longer viewed as a benign provider, but rather more as an Orwellian "big brother." A corollary here is the disengagement from civic, professional, and community networks (e.g., Putnam 2000). It is likely, however, that such networks were partially substituted by more expressive (fitness clubs, meditation gatherings) or more affective (friendships) types of social capital. Values of work and socialization equally display a profound shift in favor of the expressive traits, and above all away from respect for authority. In the work sphere, one is no longer satisfied with good material conditions (pay, job security, vacations), but expressive traits are more often being valued (e.g., contact with others, challenging and innovative work, variation in tasks, flexible time). Obviously this "anti-Fordist" orientation was initially the result of rising education and the growth of white-collar employment (e.g., Kohn 1977), but it has now spread to all social classes and types of employment. A close parallel can be found in the domain of socialization (e.g., Alwin 1989): all elements typical of conformity (obedience, order and neatness, thrift and hard work, traditional gender roles, religious faith) and those linked to social orientations (loyalty, solidarity, consideration for others) have gradually given way to expressive traits that stress personality (being interested in how and why, capability of thinking for oneself, self-presentation, independence, and autonomy). Needless to say, the quest for more symmetrical gender relations fits within this articulation of higher-order needs and expressive social roles.

\section{One transition or two?}

Evidently the higher-order needs can only be articulated once the lower-order ones have been sufficiently met. Similarly the SDT squarely stands on the shoulders of its predecessor, the first transition. But to consider the features of the second demographic transition as "secondary," as suggested by Coleman, or as part and parcel of a single transition, is another matter. My problem with these views is that they fail to realize both the magnitude of the contrast and the importance of the societal implications for the future.

More specifically, the "one transition only" view fails to recognize that the first and second transitions are sufficiently differentiated and even antagonistic in terms of most family-formation variables (including fertility motivations). The "unitarian" view furthermore misses the point that the first and second transitions correspond to two distinct historical phases, have a distinct "logique sociale," and are buttressed by distinct patterns of political organization. In short, the "one transition" view simply blurs history. 
Last but not least, the demographic implications of the SDT for the future are fundamentally different from the equilibrium implied by the first transition. SDT theorists expect much rougher seas ahead: (1) more pronounced population aging as a result of sub-replacement fertility, hence more pressure on the welfare state, (2) greater reliance on immigration and consequently a further expansion of multi-ethnicity and multi-cultural traits in societies, (3) less stress on social cohesion (e.g., Surkyn and Lesthaeghe 2004), and (4) a greater incidence of family instability and concomitant social problems (e.g., poverty among singles or in one-parent households). As Kathleen Kiernan (2001) warned, "the SDT is not kind to all."

So far, I have explained why it makes sense to distinguish the successive historical steps from one transition to the next. In the following section I address the geographic diffusion of the SDT to other parts of Europe.

\section{Is the second demographic transition only a Northern and Western European idiosyncrasy?}

Toward the end of the 1980s, several features of the SDT seemed to stop at the northern slopes of the Alps and the Pyrenees: the incidence of cohabitation in Southern European countries remained low, and the rise in extramarital fertility was either absent or modest. Instead, younger adults predominantly remained in or stayed attached to their parental homes. Also until around 1990, patterns of early marriage and fertility had been maintained in Central and Eastern Europe. Twenty years ago, one could still argue that the SDT would remain a "parochial" idiosyncrasy, limited to Western and Northern Europe. Admittedly, features of the SDT had emerged in European populations across the oceans (in Canada, Australia, New Zealand, and the US), ${ }^{4}$ but they failed to cross two geopolitical divides on the old continent.

\section{Central and Eastern Europe}

In Central and Eastern Europe, this picture changed completely after the collapse of the Communist regimes in 1989. All SDT features emerged simultaneously: ages at first marriage, which had remained quite young during the preceding era, started increasing, premarital cohabitation rose, and so did proportions of extramarital births. In tandem with later union formation came a prolonged postponement of fertility at all ages and parities, leading to a precipitous drop of period fertility indicators. TFRs fell below 1.5 children and even below 1.3. A new term was coined: lowest-low fertility (Kohler, Billari, and Ortega 2002). Period fertility measures evidently can be deeply depressed when such systematic postponement occurs. However, the degree to which recovery can occur in cohort fertility is still uncertain, as is the amount of recovery in prospective period TFR levels. But the outcome seems to be that fertility will stay well below replacement in any event. In 2002, all former 
Communist countries still had TFRs below 1.35, and as low as 1.10 (Ukraine). The sole exceptions were Albania, with a TFR probably around 2.0, and the Republic of Macedonia and Serbia-Montenegro, with levels around 1.75.

Few observers in the former Communist countries initially thought that this could be the start of a second demographic transition. The older generation of demographers was highly skeptical about the SDT concept to start with, and remained convinced that these pronounced marriage and fertility postponements were exclusively the consequence of the economic crisis. The UN Economic Commission for Europe initially held this view as well (UNECE 1999, 2000). And the transition to capitalism was indeed a painful one: the end of guaranteed life-long employment, a reduction in labor force activity rates for women, a steep drop in the standard of living, a decline in state support for families, a privatization of the housing sector, and in several countries also a highly visible rise in poverty. But there was also a countercurrent of younger demographers, mainly in Russia (Zakharov and Ivanova 1996; Zakharov 1997) and especially the Czech Republic (Zeman, Sobotka, and Kantorova 2001; Rabusic 2001; Sobotka 2002), who thought that, the economic crisis notwithstanding, a second demographic transition could be in the making. In fact, by the late 1990s the economies of several of former Communist countries were recovering along with per capita incomes. But there was no return to earlier patterns of marriage, nor an end to fertility postponement. Also the steady rise in extramarital fertility, which had often started before 1989, continued and even accelerated (see Figure 1). Of 18 such countries, only five still had proportions of extra-

FIGURE 1 Proportion of extramarital births (percent), selected European countries, 1950-2008

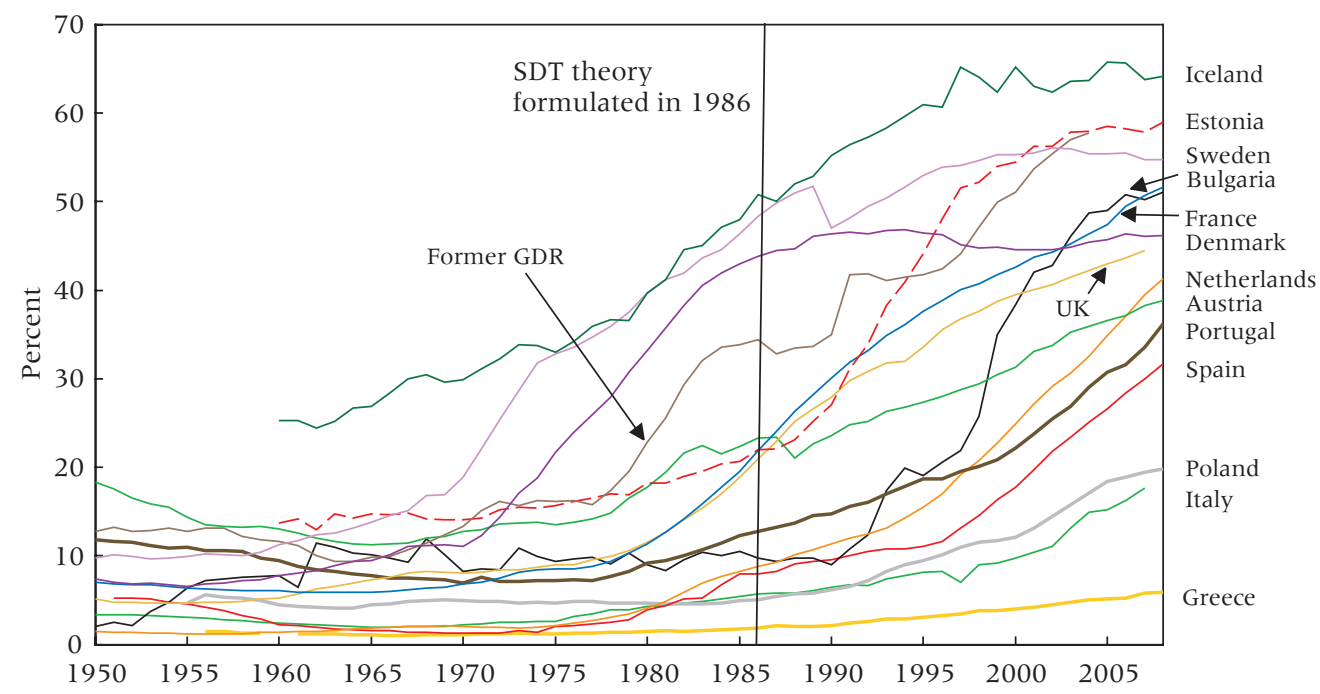

SOURCE: Compiled by T. Sobotka on the basis of Council of Europe and Eurostat data. 
marital births below 20 percent in 2002. At the upper tail of the distribution, four had already reached Northern European levels with proportions above 40 percent (Council of Europe 2004). Fifteen years earlier, these countries had percentages between 3 and 15, and only the former East Germany stood out with 34 percent extramarital births in 1985. These rapid increases are admittedly also the result of the rise in proportions of first births in the declining total, but they undeniably indicate that childbearing within cohabiting unions is spreading in Central and Eastern Europe.

The verdict seems to be that the economic crisis had indeed destabilized the earlier demographic regime, but also that the SDT had been nascent before 1990 and that is it developing further. In other words, the SDT is emerging in Central and Eastern Europe as a feature that is there to stay, just as in the West. Once more it is emerging as a salient characteristic of capitalist economies and of cultures that recognize the primacy of individual autonomy and that develop the higher-order needs.

\section{Southern Europe}

As I indicated earlier, the demographic patterns of Southern Europe, from Portugal to Greece, have been considered an exception to the theory of two successive demographic transitions. In fact, in one crucial respect these countries were not an exception at all, since their marriage and fertility postponements were even more pronounced than in Western and Northern Europe. The postponement started later than in the West, but its intensity was striking. Moreover, as was also true for a few Western European countries like Austria and to some degree Germany, cohort fertility patterns in Southern Europe scarcely exhibited signs of fertility recuperation after age 30 (Lesthaeghe 2001; Frejka and Calot 2001). This means not only that progression to the second or third child is rarer than in Northern and Western Europe, but also that in the younger female cohorts larger proportions-typically in excess of 20 percent-will not experience parenthood at all. This combination of factors is a recipe for prolonged lowest-low fertility, rather than for a temporary dip and swift return to replacement level. Hence, seen from the fertility perspective, Southern Europe followed the postponement trends in nuptiality and fertility, and these countries are by no means exceptions to these core SDT features.

What made the Southern European starting pattern of the SDT so exceptional when compared to their Northern neighbors was the absence of home leaving in favor of single living or premarital cohabitation. Young adults simply continued living with their parents for longer periods. Furthermore, marriage remained the predominant precondition for childbearing. In other words, one of the SDT features was missing. Persuasive explanations for this difference have been offered by Palomba (1995), Micheli (1996, 2000), and Dalla Zuanna (2002). The last author also directly refers to Reher's (1998) 
distinction between the historically "strong family system" of Southern Europe and the traditionally "weak family system" of Western and Northern Europe.

In the weak family system, children can leave the parental household before marriage, and then they fend for themselves in an interim period prior to marriage. Historically, they became servants, apprentices, landless and/or seasonal agricultural laborers, industrial workers, soldiers, seamen, or clergymen. In contemporary Northern and Western Europe, welfare provisions still favor this earlier independence through sufficient student housing, scholarships, student transportation subsidies, youth unemployment benefits and employment programs, and even guaranteed minimum incomes for single persons older than 18 no longer living at home. The result is still earlier home leaving for independent living, sharing, or cohabiting. Greater gender equity fosters higher female employment rates, and vice versa. Household standards of living are based on dual incomes, but women can take off periods of time for family reasons (e.g., maternity leave, optional leave for childrearing or caring for a sick partner or parent). Either or both partners can also opt for part-time employment, an option enhanced by labor market flexibility. Furthermore, this system is compatible with the shift toward expressive values and roles, and it creates less tension between self-fulfillment and parenthood.

In the strong family system, familial ties and solidarity-even allegiance to family alliances, as in Southern Italy-are more persistent throughout life. Men and women only leave the parental family to marry, and sons can even bring their wives into the parental home. Men are looked after by their mothers and then immediately thereafter by their wives. Traditional gender roles persist and men shun housework. Family bonds continue to function throughout life, both between siblings (e.g., in business) and between generations. Older parents and relatives are still taken in by their children. Mediterranean societies furthermore developed their welfare provisions on the assumption that strong familial solidarity would persist, and very few provisions allow young adults to become economically more independent. In addition, housing falls largely within the private sector, and most couples want to become home-owners. The resulting high housing costs tend to retard the departure from home. Home leaving occurs much later than in Western and Northern Europe, and there is little cohabitation or childbearing among unmarried couples. Instead, young adults continue to live in their "gilded nests" provided by caring parents. And for women, motherhood also means dropping out of the labor force, not only because this is to be expected from a "good mother," but also because child care facilities are scarce and returning to an earlier job is more difficult. Opportunity costs are increased as a consequence of the persistence of traditional role patterns and inflexible labor markets. The ultimate outcome is what Dalla Zuanna calls "a Pyrrhic victory 
of the strong family system," because, paradoxically, it will eventually disappear for lack of adaptive capacity and absence of children.

But does history stop here? Will the Mediterranean demographic system maintain this hitherto characteristic lack of alternative household types among younger adults? The presence of such households is not routinely flagged by European registration systems, hence we have to wait for special surveys (or an occasional census) to monitor changes in household forms. The European Fertility and Family Surveys (FFS) of the early 1990s are outdated by now, because they reflect living arrangements of the 1970s and 1980s. The major exception is that most European countries still distinguish between births occurring within marriage and out of wedlock. From this information we cannot infer the respective shares of extramarital births contributed by single mothers and by cohabiting couples. But, as the record has shown for most continental Western and Northern European countries, the larger share has gone to the latter. Hence, extramarital fertility provides a useful early indicator of progression to one of the later phases of the SDT, namely procreation within cohabitation.

After a long period at low levels, nonmarital fertility started a steady upward trend in Southern Europe. Portugal, which historically had a tradition of cohabitation and out-of-wedlock fertility (cf. Livi-Bacci 1971) in its southern provinces, is the exception. Portugal had steadily increasing proportions of extramarital births since the 1970s. And when compared to figures for Western European countries, the rise in extramarital births in Portugal predates the corresponding increase in the Netherlands, Belgium, Germany (FRG), and Switzerland. Spain is a more classic example of a late start and from a lower level, but the Spanish trend now runs parallel to Portugal's, and in 2002 Spain's share of extramarital births was larger than Switzerland's. Apparently, the Pyrenees and the strong family system were not as formidable an obstacle to the diffusion of the SDT as had been thought.

A few more surprises may be found in Southern Europe. The first is a steep and continuing increase in out-of-wedlock fertility in Malta, rising from 2 percent in 1990 to 15 percent in 2002. The second has been a steady increase in extramarital fertility in Italy. Starting from very low levels in the 1960s, the figure has now reached 15 percent. Judging from this record, the family system in Italy may be stronger than in Portugal, Spain, or Malta, but it is clearly not unaffected by the SDT. In fact, Italy is now catching up with the most "conservative" country in Western Europe, Switzerland, which has widespread cohabitation but a low level of extramarital fertility, at 10 percent of all births. Results from the latest Italian census indicate that in 2000 cohabitation was widespread in many northern areas, both rural (e.g., Aosta, EmiliaRomagna) and urban (e.g., Milan). Third, the percentage of nonmarital births has also reached the 10 percent level in 2000 in the Republic of Macedonia. Finally, the last part of the Mediterranean "strong family belt," that is, Greece 
and Cyprus, also shows a rise in nonmarital births, although the levels are still too low to justify any firmer conclusion. The Eastern Mediterranean thus constitutes the last area to be affected by the second demographic transition. Compared to a decade ago, history has moved in the predicted direction in Southern Europe as well.

\section{Western and Northern Europe}

To end this section on the European diffusion of the SDT, I would like to point out that the process is not yet complete in Western and Northern Europe either. As the extramarital fertility indicator shows, proportions of births out of wedlock are still increasing in most countries considered in Figure 1, including those with the highest incidence, namely Iceland, Sweden, Germany, Norway, and France. Apparently the prospect of 60 percent of all births being born outside marriage is a possibility for these vanguard countries. Yet, it should also be pointed out that there is a distinctly more conservative version of the Western European SDT in which single living, sharing, and cohabitation have all become common, but where marriage is still connected to the transition to parenthood. The parenthood decision often comes first, and the marriage decision follows. In such situations extramarital fertility is also rising but more slowly and at lower levels. Good examples of this conservative variant are Switzerland, Germany, Belgium (mainly Flanders), and to some extent the Netherlands. Ireland, by contrast, seems to have made the jump from the more conservative category to the more advanced SDT category of countries. In fact, Ireland has already crossed the 30 percent level, whereas in 1980 it barely had 5 percent of births out of wedlock.

\section{Historical path dependency and growing heterogeneity in the pattern of the SDT}

So far we have documented that the features of the SDT did not stop at the borders of Northern and Western Europe and that the new pattern began to thrive after the crisis of the early 1990s in former Communist Central and Eastern Europe. But in the meantime it has become increasingly evident that the mixture of SDT ingredients may vary widely depending on context. Substantial within-country and between-country contrasts can be found (e.g., Billari and Kohler 2004; Neels 2006; Lesthaeghe and Neidert 2006; Sobotka 2008; Lesthaeghe 2009), and the same holds between educational categories (e.g., Neels 2006, 2009). Obviously such variations reflect historical path dependency, and these play just as large a role in the unfolding of the SDT as they did in producing leads and lags during the first transition. Hence, the SDT theory should not be taken as a teleological grand script with a standard scenario. On the contrary, it is a more general narrative that leaves room for 
many different sub-narratives, each of which is anchored to specific empirical evidence.

\section{Dissociations between the rise of cohabitation and the postponement of parenthood}

From the beginning of the SDT, countries have exhibited striking differences between the timing of the onset of the rise in premarital cohabitation and the onset of fertility postponement. In Western Europe, for instance, the two were timed rather closely together, but in Southern Europe there was a major lag of about 20 years, with rising cohabitation starting much later.

Spatial dissociations within a given country are equally common. In the United States both state- and county-level characteristics of household formation first split along two dimensions: characteristics of young households (indicators pertaining to teenage fertility, young single mothers, grandchildren in household) and an SDT dimension (Lesthaeghe and Neidert 2006). Problems along the first dimension are a typical American feature associated with low education and poverty (with milder versions found in the UK and Australia as well). But when the American SDT dimension was examined more closely, two spatial sub-dimensions appeared: the North Atlantic states were most advanced with respect to postponement of fertility in the age group 20-29, with clear sub-replacement fertility among non-Hispanic whites, whereas in the vanguard with respect to cohabitation were the liberal Mountain states (Colorado, Arizona) and the Pacific states. Furthermore, postponement of marriage and fertility was strongly associated with high education levels for both sexes, whereas cohabitation was connected to higher proportions born abroad or out of state. At the other end of the distribution, middle and low levels of cohabitation remained closely correlated with earlier fertility in the prime childbearing ages and with higher non-teenage fertility in the Southern, Appalachian, and the conservative Mountain states (especially Utah and Idaho), and in the Great Plains. The overall image is that of a first set of states where the SDT has not yet taken off, a second set where both cohabitation and fertility postponement hold the middle ground, and a leading SDT set that splits into two groups depending on whether they are in the vanguard either of the postponement of parenthood or of the spread of cohabitation.

A spatial analysis of Belgium (Neels 2006; Lesthaeghe 2009) at the level of arrondissements produced an even clearer picture. The rise of cohabitation and out-of-wedlock fertility after 1970 mirrors the spatial continuity of the maps of the marital fertility decline and the rise of contraceptive practice during the first demographic transition (1880-1940), and they are an almost perfect correlate of secularization levels from 1860 through 1960. The map of fertility postponement after 1970, by contrast, bears no resemblance to this long historical secularization, but typically reflects levels of higher education 
and employment among women. The latter feature is also strongly echoed in the micro-level data analyzed by Neels $(2006,2009)$, which show that better-educated women have been the dominant postponers ever since World War II.

The partial dissociation between the new household forms and fertility postponement in the United States and the complete dissociation of these features in the Belgian spatial pattern of the SDT point toward different causes. In both countries cohabitation spreads faster in more secularized areas and bears only a weak relationship to education levels and female labor force participation. Postponement of parenthood is more strongly associated with the latter structural factors. Within the framework of Coale's "ready, willing, and able" paradigm, the limiting factor for the rise in cohabitation seems to be of the "willingness" type, meaning that it depends more strongly on moral acceptability and legitimacy rather than on the calculus of advantage. This is understandable since cohabitation initially ran counter to the prevailing moral and legal codes in many countries. The postponement of parenthood, by contrast, is less conditioned by moral objections and more responsive to material conditions, hence linked to structural factors associated with the "readiness" condition.

The strong connection between cohabitation and liberal values derives support not only from spatial analyses such as the ones just cited, but equally from individual-level data. That evidence, to be discussed briefly in the next section, draws on numerous empirical studies (see Lesthaeghe 2002 for an overview and citations).

\section{Value orientations and household choices:} Micro-level evidence

The initial article on the second demographic transition (Lesthaeghe and van de Kaa 1986) posited that the new living arrangements, and cohabitation in particular, were the expressions of secular and anti-authoritarian sentiments of younger cohorts who held a more egalitarian world view and placed greater emphasis on expressive values. Also during the 1980s political scientists analyzed the correlates of Inglehart's "post-materialist" orientation (Inglehart 1990; van Rijsselt 1989). Both the Eurobarometer surveys in the EU and the three rounds of the European Values Studies (EVS) provided data for detailed empirical research on attitudes and values for various social groups, including those based on living arrangements (e.g., Lesthaeghe and Moors 1995). Particularly the EVS data of the 1999-2000 round proved useful for study of the SDT, since for the first time questions about ever experiencing cohabitation or divorce were incorporated along with current household status. This meant that the large group of currently married respondents could be divided into those who did and did not experience cohabitation or divorce. These refine- 
ments allowed clear distinctions in values orientations (see Lesthaeghe and Surkyn 2002; Surkyn and Lesthaeghe 2004).

Also in the United States, statistical associations between living arrangements and specific value orientations drew attention. It was realized not only that cohorts were steadily progressing to higher levels of "post-materialism" and secularism, but also that a recursive relationship existed between demographic choices and values orientation. As Thornton and colleagues showed $(1985,1992)$, greater secularism fostered choices in favor of premarital sex and non-traditional household formation patterns, but the latter also reinforced further secularization. In other words, a selection into various types of behavior occurred based on existing values, followed by an affirmation or strengthening of these values based on the behavioral choice. Clearly, the statistical associations between value orientations and the various types of households are merely the "footprints" of this ongoing process of selection followed by affirmation or negation of values. Panel data with values measurements and transitions in household living arrangements are needed to disentangle the two directions of causation. American social scientists took the lead in organizing panel surveys, and it is mainly on the basis of these that the recursive model of selection/adaptation could be checked (e.g., Waite, Goldscheider, and Witsberger 1986; Axinn and Thornton 1993; Barber 2001; Clarkberg 2002). More recently, a few European panel surveys measure various value orientations at successive waves, and they too lend themselves to disentangling the causal components of the recursive relationship (e.g., Moors 1997; Jansen and Kalmijn 2002).

The outcomes of analyses of these cross-sectional and panel data can be summarized as follows:

1) Secular, egalitarian, and anti-authoritarian orientations, expressive values, and values stressing individual autonomy are strong predictors of life courses that include "unconventional" states such as premarital cohabitation and parenthood among cohabitors. These effects are net of structural effects linked to education, socioeconomic status, employment, or degree of urbanness.

2) Cohabitants without children tend to exhibit the extreme non-conformist values profile, including greater gender symmetry, less intolerance to all types of minorities, greater protest-proneness, but also greater tolerance for breaches of civil morality.

3) Marriage and parenthood are associated with major readjustments of value orientations in the conventional and conformist direction.

4) Married parents who never cohabited display by far the most conservative attitudes.

5) Any earlier cohabitation experience leaves a more permanent imprint in the non-conformist direction, even after marriage and parenthood have been achieved. 
6) Divorce produces a departure from the stability of conventional opinions held by married parents. ${ }^{5}$

I note, finally, that these associations at the micro level are found throughout Europe. They hold just as well in countries that have progressed far along the SDT as in those that are recent starters.

\section{Fertility and the SDT: Postponement and recuperation}

The typical explanation for the fertility decline associated with the SDT is the postponement of parenthood and the shifting of fertility to older ages. This explanation is reflected in the Bongaarts-Feeney (1998) formula used to upwardly correct the current period total fertility rate (PTFR) for this tempo shift. In this expression, however, the authors have no room for differential subsequent recuperation of postponed births. They use the standard assumption of adjusting current period parity-specific TFRs (PTFRi) and inflating these by the complement of the annual rate of parity-specific postponement observed in the last few years. Reality is a bit more complicated. Not only is the rate of postponement variable over time, but the European experience clearly shows a great deal of heterogeneity in the amount of recovery of fertility at later ages. This is most clearly shown in the comparison of cohort fertility profiles, either parity-specific or for all parities combined.

On the one hand, there are countries where each cohort postpones childbearing longer than its predecessor, but where the ultimate fertility (i.e., the cohort total fertility rate, or CTFR) is fairly constant, because of the recuperation at older ages of almost all postponed births. The Netherlands is a typical example of this outcome, but it also holds for the Scandinavian countries, France, and Belgium. Also, period TFRs in these countries will bounce back when the tempo shift stops. On the other hand are cases where such recuperation is absent or modest, and where cohort TFRs continue falling as long as the postponement continues. Moreover, these cohort TFRs will remain well below replacement level. Typical examples of this pattern are the Mediterranean countries and the German-speaking populations of Western Europe (cf. Lesthaeghe 2001; Frejka and Sardon 2004; Sobotka 2004, 2008). For the former Communist countries, differential recovery may now be observable too. These countries experienced their major postponement trend during the 1990s, and couples who were then in their early 20s are now old enough to exhibit the presence or absence of such a correction at later ages. The bottom line here is that initial differences in period TFRs among European populations were indeed largely due to differential rates of postponement, but that differential recuperation will now increasingly determine the period TFRs during the first two decades of the twenty-first century (Sowers and Lesthaeghe 2008). The degree to which this recuperation will occur depends on varying historical and current circumstances and policy measures. 
At the time of the original formulation of the SDT theory, the systematic postponement of marriages and first births was already underway in Western Europe. Van de Kaa and I predicted that the new cultural shifts toward the expressive needs in tandem with increased individual autonomy would sustain this demographic tempo shift. The outcome would be "structural" sub-replacement fertility instead of cyclically oscillating fertility around replacement level. At that time, we did not predict the coming of lowest-low fertility or period TFRs below 1.3 children, nor were we able to differentiate between strong and weak recuperation. The latter feature would only gain our attention more than a decade later (Lesthaeghe and Willems 1999; Lesthaeghe 2001) and independently from the SDT theory.

Nevertheless, van de Kaa (2002) and Sobotka (2008) showed that the SDT was indeed a good predictor of postponement, capable of neatly aligning countries along a positive slope: the higher the level of Inglehart postmaterialism (van de Kaa) or the higher the composite index of SDT values (Sobotka), the higher the mean age of women at first birth or the earlier the onset of fertility postponement. To elucidate this point, I reproduce the original graphs of these authors in Figures 2 and 3.

FIGURE 2 Relationship between the mean age at first birth around 1998 and the Inglehart index of postmaterialism in 1990

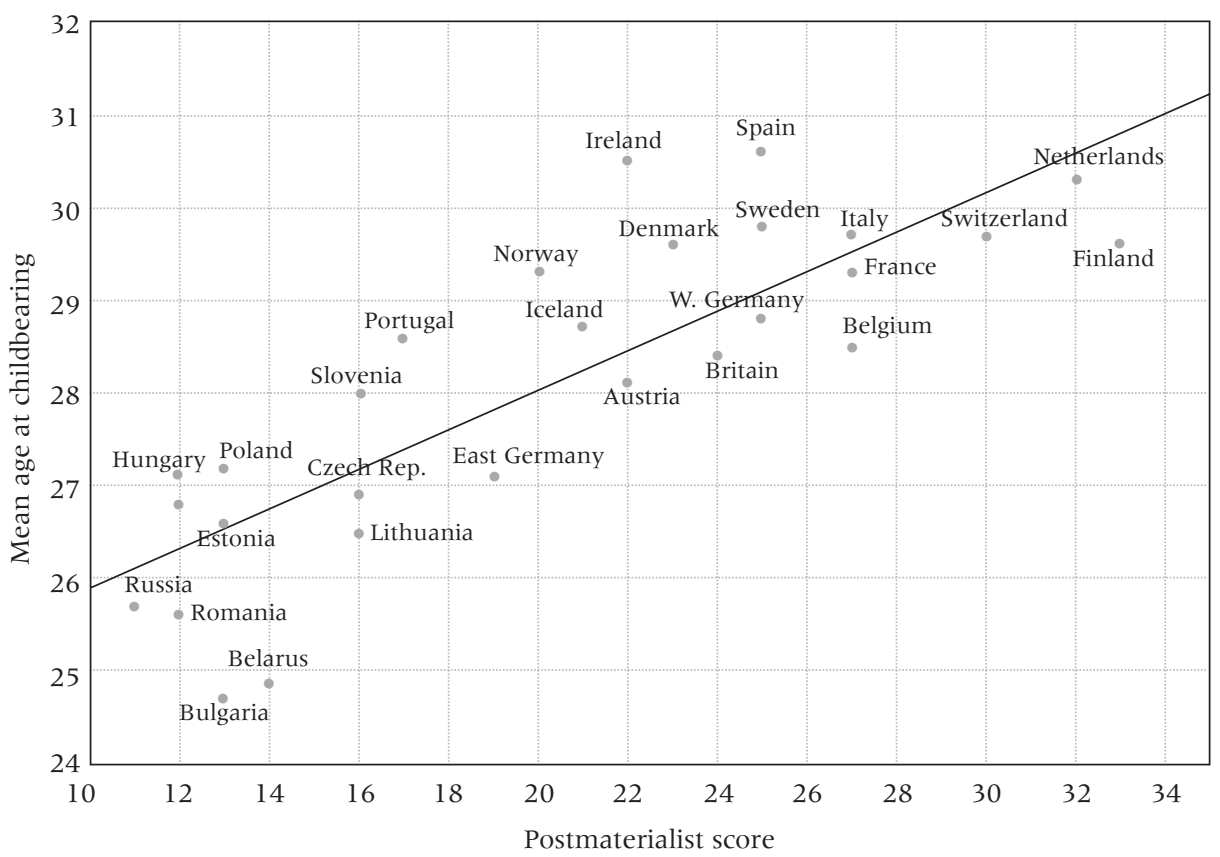


FIGURE 3 Relationship between a composite index of SDT values in 1999-2000 and the date of onset of the postponement of first births

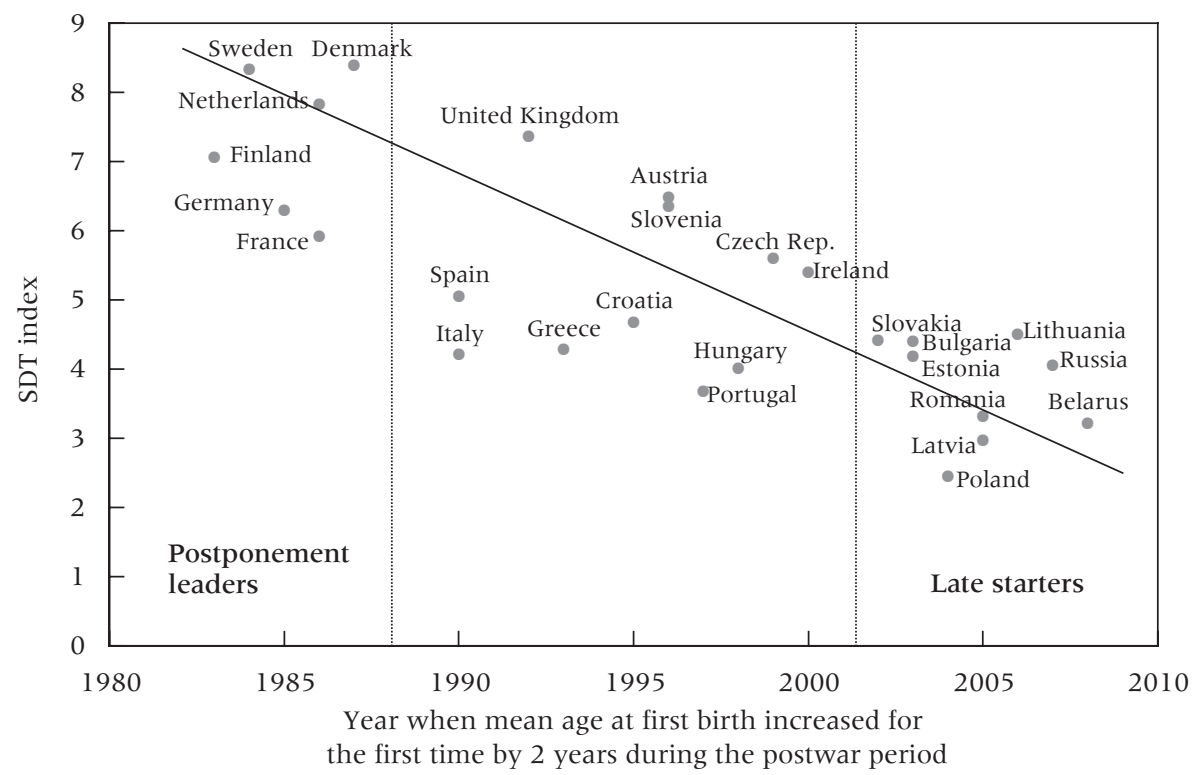

SOURCE: Sobotka (2008). The SDT index is from Sobotka (2008, pp. 86-87).

When the same exercise is repeated for period TFRs, the original SDT/ postponement relationship vanishes, and a positive correlation emerges when total fertility is connected to the SDT values index, ${ }^{6}$ as shown by Sobotka in Figure 4. By 2000 the countries with high SDT values had by far the highest period fertility levels in Europe, and some had come very close to replacement level. ${ }^{7}$ None of them ever fell below a period TFR of 1.5, and by 2007 Belgium, Denmark, Finland, Sweden, Norway, the UK, France, and Ireland all had period TFRs above 1.8 (Prioux 2008). The positive relationship with the SDT values index in Figure 4 is in fact the result of "split correlation" and is produced by two distinct scatters. The collection of cases on the right side corresponds to countries with an early start in fertility postponement and a strong recuperation of fertility forgone at earlier ages. The cases on the left side with much lower period TFRs are mainly cases where postponement started later and recuperation of fertility was weak (German-speaking populations, Southern European countries, and most formerly Communist countries).

For the SDT theory to be relevant for the twenty-first-century fertility differentials in Europe, it needs to incorporate explanations for differential recuperation as well. With the benefit of hindsight it seems that certain aspects of the causes that generate the SDT have fostered postponement of 
FIGURE 4 Relationship between a composite index of SDT values in 1999-2000 and 2004 period total fertility rates

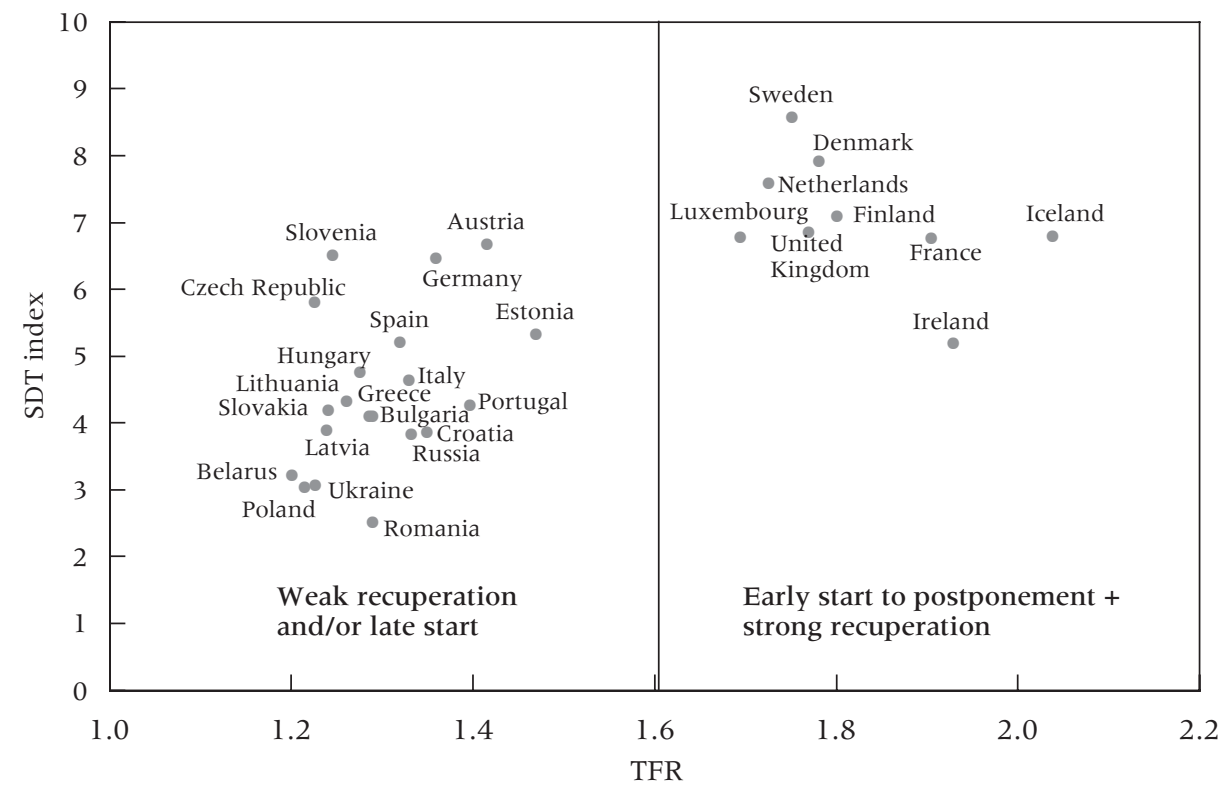

SOURCE: Sobotka (2008, p. 52).

parenthood and hence tended to lower period fertility levels, whereas other aspects have facilitated a more complete recuperation, thereby returning period TFRs to higher levels. I will now seek to clarify these opposite effects with reference to the factors sketched in Figure 5.

On the postponement side I place social and economic factors associated with prolonged education and longer preparation for careers in deregulated and globalizing labor markets. However, to these "mechanical" (e.g., prolonged formal education) or structural factors can be added cultural features such as greater aspirations for self-realization, a greater tendency to keeping an open future, or higher consumption and leisure aspirations. The former are typical structural features of post-industrial societies, whereas the latter are more closely connected to the expressive values orientations. Together these two sets of factors have a negative effect on fertility operating via their postponement effect.

Subsequent recuperation of fertility, on the other hand, may be considerably enhanced by factors that facilitate the combining of work and parenthood for women and men or that alleviate the opportunity costs of parenthood and family building. A further distinction can be made by referring to (i) historical household patterns and gender relations (e.g., the contrast between the strong and weak family types, existence of neolocal marriage or of three-generation co-residence, etc.) and (ii) the type of organization and 
FIGURE 5 The double effect of SDT-related factors on total fertility

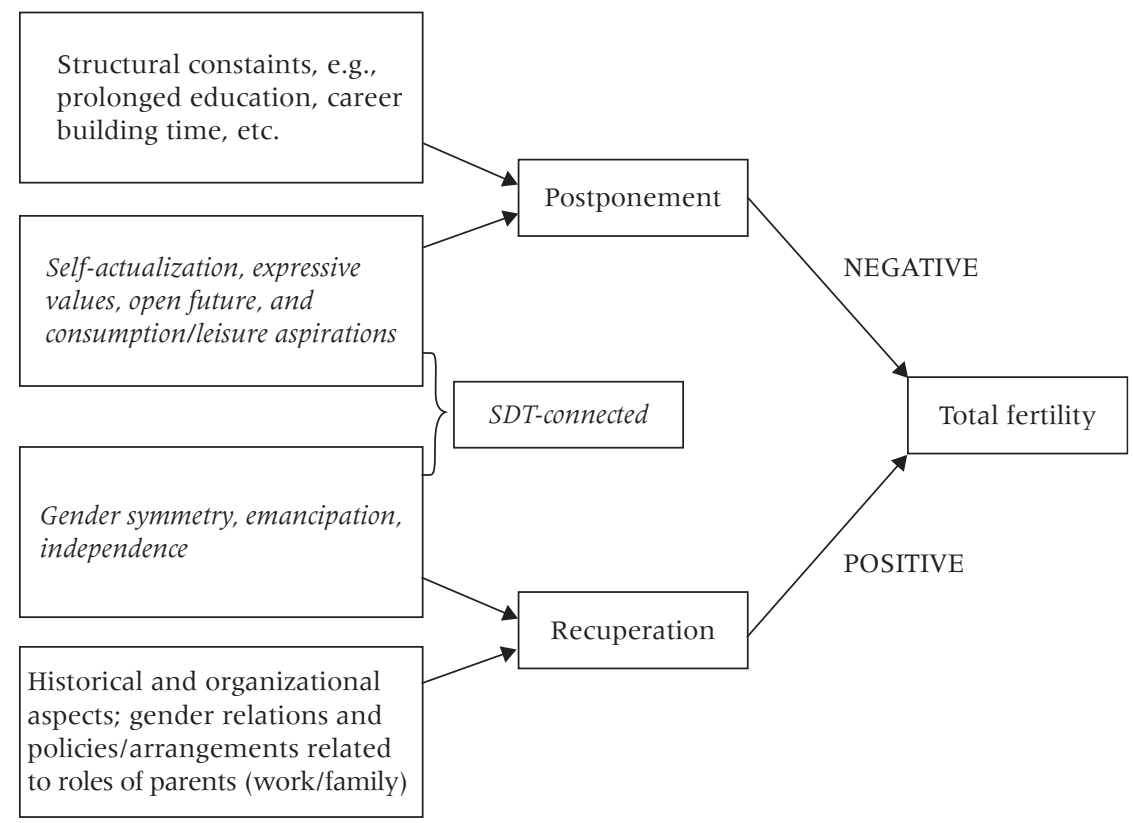

magnitude of welfare provisions (e.g., child allowances, parenthood leave, work interruptions for family reasons) and other organizational features (e.g., school opening hours and day care provision). These structural features equally have to be seen in interaction with value orientations connected to self-reliance of young adults (and of men in particular) and to gender symmetry in daily life. The separate impact of each of these factors is not easy to assess, but when taken together substantial differences in patterns of fertility recuperation can result. In fact, the "split correlation" noticed in Figure 4 may in part be due to national contrasts in this respect. Just focusing on Western and Southern European countries, for instance, Thévenon (2009) notes striking differences in factors that alleviate time pressure on parents of young children. Not surprisingly, all countries with higher fertility levels resulting from strong recuperation have better-adapted services and much longer opening hours of facilities (services de garde) for infants and toddlers, for preschool children in kindergarten, and for children in primary school.

To conclude, the original formulation of the SDT theory predicted-apparently correctly-a long period of below-replacement fertility, but it did not predict the current discrepancy between levels close to replacement and levels far below it. The current heterogeneity in Europe is indeed due to differences in the timing of the onset of fertility postponement, but increasingly also it is the result of differences in the degree of fertility rebounding at older ages. The cultural components of the SDT theory appear to be operating in 
opposite directions: some foster postponement and hence lower fertility, while others support greater recuperation of fertility. The weight of context-specific features, both of a historical and an organizational nature, is again considerable, and consequently SDT sub-narratives are necessary to encompass that diversity.

\section{Can the SDT spread to non-Western populations?}

It is widely accepted that the first demographic transition is a worldwide phenomenon. Everyone also realizes that the first transition can begin at just about any level of economic development, and in strictly rural as well as urban societies. But will the second demographic transition be equally universal? Or, as Coleman expects, will it remain a regional idiosyncrasy? Obviously, at this stage we can only speculate about the probabilities of such a universal diffusion, in the same way that one could only speculate in the 1950s and 1960s about the eventuality of pervasive fertility control emerging in the then-developing countries. However, if we are looking for evidence of the second demographic transition beyond the European cultural sphere but in countries wealthy enough to have undergone some Maslowian drift, we may indeed find suitable testing grounds. Several industrialized and urbanized Asian countries are therefore of direct relevance.

Before considering the detailed evidence, one should be reminded that identification of the SDT requires the presence of several features:

1) Sub-replacement fertility must be linked to postponement of marriage and childbearing.

2) Ages at marriage must reflect a growing prominence of free partner choice and female autonomy.

3) Premarital cohabitation must become more common and more widely acceptable.

4) At both the macro level and the individual level, connections must exist between demographic features and value orientations.

Note, however, that the demographic characteristics of the SDT do not necessarily occur simultaneously, but that lags are likely to emerge. Premarital cohabitation and parenthood among cohabitors, for instance, typically constitute lagging features, since they often run counter to existing moral codes.

\section{Sub-replacement fertility and postponement in Asian industrialized countries}

The criterion of a shift toward later parenthood and sub-replacement fertility is the easiest to assess since national demographic statistics provide clear evidence on the course of period and cohort fertility. Japan, South Korea, 
Taiwan, Hong Kong, and Singapore all have very low period TFRs at present. Hong Kong's period TFR is around 1.0, Singapore's is a marginally higher 1.1, and Taiwan, Korea, and Japan are in the 1.15-1.25 range (CIA data base 2008). In all cases these lowest-low fertility levels are the result of widespread postponement with little or no recuperation of fertility at later ages. Obviously, there is some recuperation of first births, but this is offset by further declines at higher parities (see inter alia Zhang 2005; Jones, Straughan, and Chan 2009; Tsuya 2009; Frejka and Sardon 2009).

The extent of fertility postponement and the weak impact of recuperation in the lowest-low East Asian countries are seen in the trend in cohort cumulated fertility up to age 27, which is illustrative of postponement, and in cohort cumulated fertility between ages 27 and 40, which is illustrative of recuperation. The evolution of cumulated fertility up to age 27 is presented in Figure 6, and that for ages 27 to 40 in Figure 7. In these figures, I have selected three countries with early postponement but strong recuperation (France, Netherlands, Sweden), three European countries with weak recuperation (Austria, Italy, and Spain), and four East Asian countries (Japan, Hong Kong, South Korea, and Taiwan).

Figure 6 illustrates that the four Asian countries exhibit the same fertility postponement trend as found in the European countries. In fact, Hong Kong had massive postponement for the cohorts born between 1945 and 1965, whereas Taiwan and South Korea have a fast postponement tempo for the

FIGURE 6 Cumulated cohort fertility up to age 27, selected countries, 1940-1980 birth cohorts

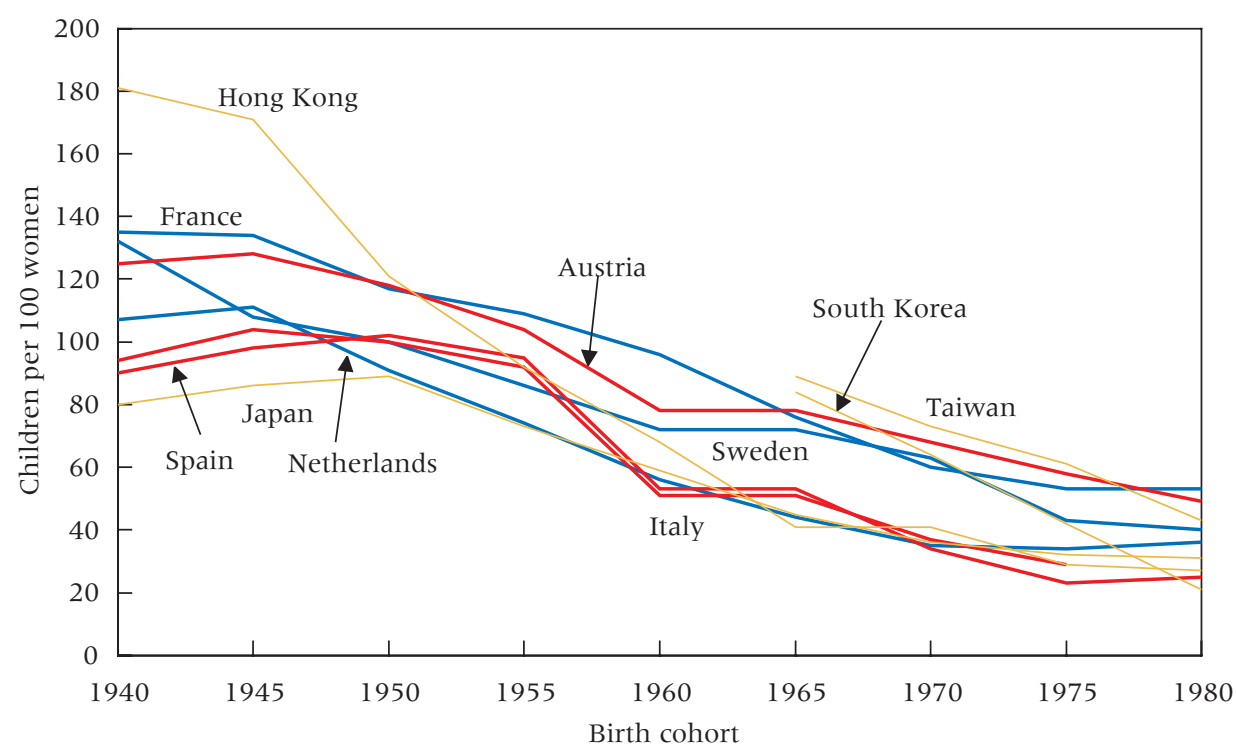

SOURCE: Frejka and Sardon (2009: Appendix 3). 
FIGURE 7 Cumulated cohort fertility at ages 27-40, selected countries, 1940-1965 birth cohorts

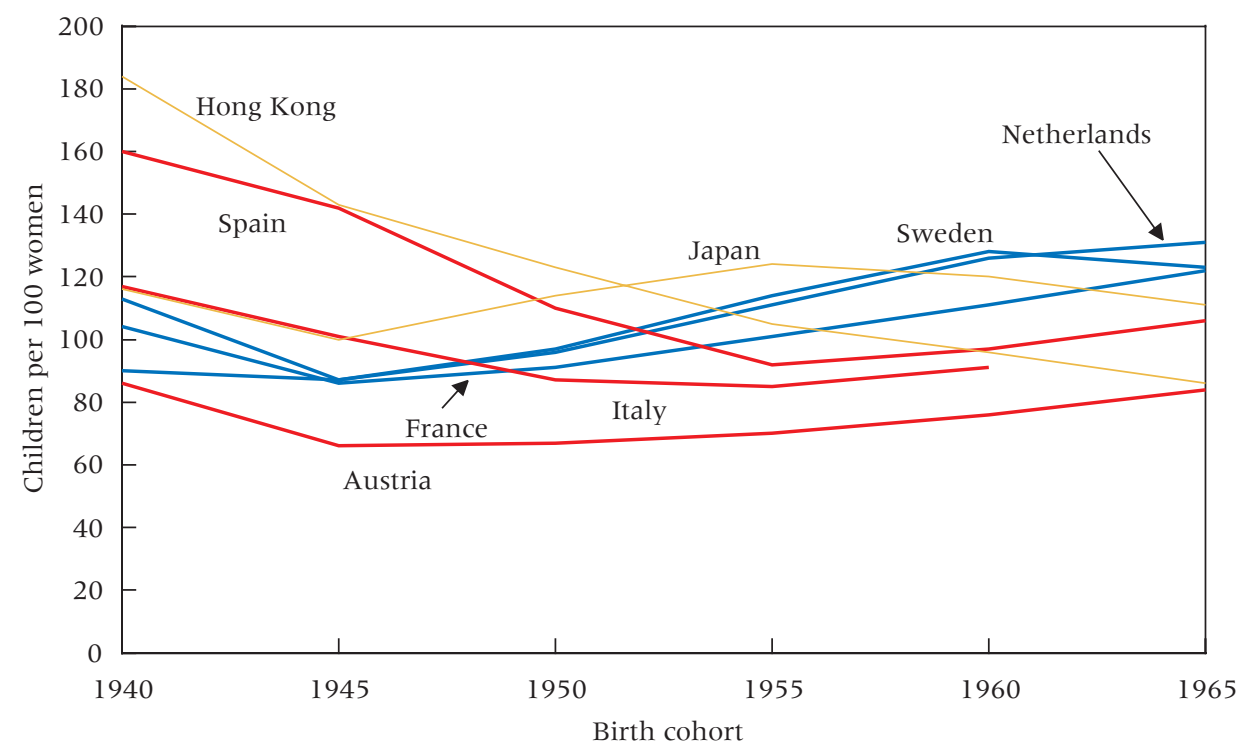

SOURCE: Frejka and Sardon (2009: Appendix 4).

cohorts born after 1965. Also note that the Hong Kong, Japanese, and Korean cohorts born in 1980 have fewer than 40 children per 100 women born before age 27 . With these figures they match the levels of Spain and Italy.

Figure 7 shows the trends in fertility in the age range $27-40$, a period during which recovery could be expected to occur. Not surprisingly, the clearest fertility increase and the highest fertility levels are found in the Northern and Western European examples used here, whereas Hong Kong has a continued fall in its older-age fertility, and Japan exhibits a reversal from a slight recovery to further postponement. This lends support to the speculation that the East Asian populations are following a "Mediterranean pattern," with rapid postponement and little recuperation at older ages, thereby sustaining a period fertility level that falls within the lowest-low category (for Taiwan and Hong Kong see Tu and Zhang 2004).

\section{The Asian marriage revolution}

Many populations in East Asia, not only those of industrialized countries, have witnessed a sharp increase in the mean ages at marriage for both sexes. The "marriage revolution" that Goode was forecasting in the 1960s emerged in full force between 1970 and 2000, as illustrated in Table 1 by the percentages of women single at ages 30-34 and 40-44. In 2000 more than a quarter of all women aged 30-34 were still single in Japan and Myanmar, and about 
TABLE 1 Increases in percentages of never-married women between 1970 and 2000, ages 30-34 and 40-44, selected Asian populations

\begin{tabular}{lrrrrr}
\hline & $\mathbf{3 0 - 3 4}$ & & & $\mathbf{4 0 - 4 4}$ \\
\cline { 2 - 3 } Population & $\mathbf{1 9 7 0}$ & $\mathbf{2 0 0 0}$ & & $\mathbf{1 9 7 0}$ & $\mathbf{2 0 0 0}$ \\
\hline Japan & 7.2 & 26.6 & & 5.3 & 8.6 \\
Myanmar & 9.3 & 25.9 & & 6.2 & 14.8 \\
Thailand & 8.1 & 16.1 & 3.9 & 9.3 \\
Singapore-Chinese & 11.1 & 21.6 & 3.6 & 15.0 \\
Singapore-Malays & 3.9 & 12.2 & 1.7 & 8.2 \\
Malaysia-Chinese & 9.5 & 18.2 & 3.4 & 8.4 \\
Malaysia-Malays & 3.3 & 9.7 & 1.1 & 4.4 \\
Philippines & 8.9 & 14.8 & 6.0 & 7.1 \\
South Korea & 1.4 & 10.7 & 0.2 & 2.6 \\
Indonesia & 2.2 & 6.9 & 1.2 & 2.4 \\
\hline
\end{tabular}

SOURCE: Jones (2004: Appendix Table 1).

a fifth were not yet married among the Chinese in Singapore and Malaysia. Probably more recent figures for women in Thailand will come close to a fifth as well. Moreover, percentages single for men are typically higher than for women. For instance, in Japan in 2004, a third of men aged 30-34 were still unmarried. The classic correlates are again increasing proportions of men and women with more schooling, with employment outside agriculture and other domestic industries, less employment security, and much smaller proportions accepting arranged marriages. If, according to Jones (2004), current Western European figures of proportions single were corrected to exclude proportions cohabiting, then several Asian populations would exceed Europeans in proportions "effectively single."

Equally classic is that the postponement of parenthood follows in the wake of rising ages at marriage, particularly when out-of-wedlock fertility is low. However, shotgun marriages and births in the first eight months of marriage may become more frequent, as is already true for Japan (Tsuya 2006; Raymo, Iwasawa, and Bumpass 2008). For instance, the 2004 Gender and Generation Survey revealed that 28 percent of Japanese married women aged 25-29 had a premarital conception, and that the figure was 26 percent in the age group 30-34. By contrast, older generations, those above age 55 in 2004, had figures in the range of 4 to 7 percent (Tsuya 2006). Evidently, premarital births are still rare in East Asian societies, but premarital conceptions and shotgun marriages are not.

The Japanese shift during the late 1970s and 1980s in partnership formation patterns can be gleaned from the data collected in the early 1990s. Table 2 reproduces 1992 figures pertaining to the union formation status at various ages for successive cohorts of women. At any given age percentages married drop. By contrast, the percentages with "no event" increase for 
TABLE 2 Union formation status (percent) in 1992 at specific ages for birth cohorts of Japanese women

\begin{tabular}{lccccc}
\hline Age and birth cohort & $\begin{array}{l}\text { No } \\
\text { event }\end{array}$ & $\begin{array}{l}\text { Met } \\
\text { partner }\end{array}$ & Engaged & Married & $\begin{array}{l}\text { Number } \\
\text { of cases }\end{array}$ \\
\hline By age 20 & 64 & 21 & 5 & 10 & 2,137 \\
$1950-54$ & 66 & 22 & 5 & 7 & 1,923 \\
$1955-59$ & 66 & 24 & 3 & 6 & 1,915 \\
$1960-64$ & 72 & 20 & 3 & 5 & 1,962 \\
$1965-69$ & 62 & 34 & 0 & 4 & 1,046 \\
$1970-74$ & & & & & \\
By age 25 & 21 & 6 & 5 & 68 & 2,137 \\
$1950-54$ & 24 & 10 & 4 & 62 & 1,923 \\
$1955-59$ & 30 & 11 & 6 & 53 & 1,915 \\
$1960-64$ & 33 & 18 & 3 & 46 & 947 \\
$1965-69$ & & & & & \\
By age 30 & 8 & 1 & 1 & 90 & 2,137 \\
$1950-54$ & 10 & 2 & 2 & 86 & 1,923 \\
$1955-59$ & 12 & 6 & 1 & 82 & 961 \\
$1960-64$ & & & & & \\
By age 35 & 6 & 1 & 1 & 93 & 2,137 \\
$1950-54$ & 6 & 2 & 1 & 91 & 987 \\
$1955-59$ & & & & &
\end{tabular}

SOURCE: Japanese National Fertility survey 1992; H. Matsuo (2001: Appendix Table 11).

younger cohorts, showing that more of them experienced a longer period of being "really single." Equally striking is that the percentages who had met a partner by ages 20 and 25, but were not married or engaged, are also increasing. The table does not reveal the precise form of behavior of these younger unmarried women who had met a partner, and at that time my Japanese colleagues all assumed that these couples would occasionally meet in hotels or other such places, but would not be cohabiting. In fact, in Tokyo seminars as late as 2002 it was believed that premarital cohabitation simply did not occur in Japan. That assumption proved to be false as two independently organized surveys in the early twenty-first century indicated.

Just as in the Mediterranean countries, premarital cohabitation in Japan only emerged with a substantial time lag compared to the other hallmarks of the SDT. But initially it went unnoticed because no survey bothered to probe into the matter. In 2004, however, the first round of Japan's "Gender and Generations Survey" revealed that a fifth of all women and men aged 25-29, irrespective of their current status, had ever experienced cohabitation. Older women aged 40-44 in 2004 also reported figures above 10 percent. Table 3 gives the results in greater detail.

The other Japanese survey, organized by the Mainichi Shimbun Newspaper in 2004, confirms the appreciable prevalence of premarital cohabita- 
TABLE 3 Percent of Japanese women and men of all marital statuses reporting ever having cohabited, Gender and Generations Survey, 2004

\begin{tabular}{|c|c|c|c|c|c|c|}
\hline \multirow[b]{2}{*}{ Age } & \multicolumn{2}{|c|}{ Women } & \multicolumn{2}{|l|}{ Men } & \multicolumn{2}{|c|}{ Both sexes } \\
\hline & $\%$ & $\mathbf{N}$ & $\%$ & $\mathbf{N}$ & $\%$ & $\mathbf{N}$ \\
\hline $20-24$ & 11.7 & 322 & 11.0 & 243 & 11.4 & 565 \\
\hline $25-29$ & 20.2 & 352 & 20.6 & 289 & 20.4 & 641 \\
\hline $30-34$ & 16.5 & 345 & 20.6 & 296 & 18.6 & 641 \\
\hline $35-39$ & 15.7 & 602 & 15.9 & 472 & 15.8 & 1,074 \\
\hline $40-44$ & 11.5 & 456 & 15.5 & 400 & 13.5 & 856 \\
\hline $45-49$ & 7.5 & 504 & 10.7 & 418 & 9.1 & 922 \\
\hline $50-54$ & 7.0 & 558 & 12.1 & 523 & 9.5 & 1,081 \\
\hline $55-59$ & 5.4 & 527 & 8.3 & 492 & 6.9 & 1,019 \\
\hline $60-64$ & 4.4 & 535 & 9.5 & 498 & 6.9 & 1,033 \\
\hline $65-69$ & 2.1 & 425 & 5.0 & 489 & 3.7 & 914 \\
\hline Total & 10.0 & 4,626 & 12.6 & 4,120 & 14.6 & 8,746 \\
\hline
\end{tabular}

NOTE: Percentages are computed, using sample and response rate weights.

SOURCE: Tsuya (2006: Table 1).

tion, but, more crucially, reveals that this is not simply a short-term event. As Table 4 shows, the mean duration of premarital cohabitation reported by women is close to two years.

The conclusion from the data presented so far is that Japan is no longer an exception to major characteristics of the SDT. Add to that the rise in premarital conceptions and the divorce rate, and it becomes clear that Japan is by now definitely experiencing a second demographic transition in which the concepts of partnership and marriage are being redefined. The only missing ingredient so far is parenthood among cohabiting couples.

Moreover, Japan is not just a single outlier in East Asia. Based on two KAP ("knowledge, attitude, and practice") surveys held in Taiwan, Li-Shou

TABLE 4 Percent of Japanese women who have ever cohabited by birth cohort, mean duration, and percent followed by marriage, Mainichi Shimbun Group 2004

\begin{tabular}{llll}
\hline Birth cohort & $\begin{array}{l}\text { Prevalence of } \\
\text { cohabitation (\%) }\end{array}$ & $\begin{array}{l}\text { Mean duration } \\
\text { of cohabiting } \\
\text { unions (months) }\end{array}$ & $\begin{array}{l}\text { Percent of completed } \\
\text { cohabiting unions } \\
\text { resulting in marriage }\end{array}$ \\
\hline $1954-59$ & 10 & 22 & 64 \\
$1960-64$ & 10 & 21 & 70 \\
$1965-69$ & 17 & 26 & 62 \\
$1970-74$ & 21 & 20 & 61 \\
$1975-79$ & 21 & 21 & 40 \\
$1980-84$ & 10 & 16 & 44 \\
Total & 15 & 21 & 58 \\
\hline
\end{tabular}

SOURCE: Raymo, Iwasawa, and Bumpass (2008). 
TABLE 5 Percent of women aged 20-49 who have ever cohabited, Taiwan KAP surveys of 1998 and 2004, by current marital status

\begin{tabular}{lccccc}
\hline & \multicolumn{2}{c}{ KAP 1998 } & & \multicolumn{2}{c}{ KAP 2004 } \\
\cline { 2 - 3 } Current marital status & \% & N & & \% & N \\
\hline Unmarried & 7.8 & 731 & & 15.3 & 1,200 \\
Married & 12.6 & 2,262 & & 21.6 & 2,752 \\
Total & 11.4 & 2,993 & & 19.6 & 3,952 \\
\hline
\end{tabular}

SOURCE: Li-Shou Yang, personal communication.

Yang found that premarital cohabitation is on the rise in that country (see Table 5). If the figures for the 2004 KAP survey for married women could have been broken down into smaller age categories, then the incidence of premarital cohabitation for married women aged 25-29 would almost certainly have exceeded 25 percent, even higher than the corresponding Japanese figure.

Finally, there is also evidence for the existence of cohabitation in the Philippines (Guerrero 1995; Jones 2005), but it is not yet clear whether this is a much older form of consensual union or actual premarital cohabitation.

The empirical evidence on cohabitation for other industrialized or urban Asian societies is missing, again because it is simply taken for granted that its incidence is close to zero. As was the case for Mediterranean and former Communist Europe in the 1990s, this belief lasts until someone inserts the "ever cohabited" question in a survey. It appears that insertion of such a question is overdue in China, South Korea, Hong Kong, and Singapore, at the very least. ${ }^{8}$

Value orientations and the timing of parenthood: Micro-level evidence for three Asian populations

Several Asian countries participated in one or two rounds of the World Values Survey, which were shortened versions of their older European counterparts. These surveys are again a major source of information on secularization, civil and sexual morality, expressive values at work and in educating children, political features such as post-materialism, protest-proneness, and trust in institutions, and values regarding gender relations. Information on demographic characteristics for Asia is limited to the number of children in the household and current marital status. No questions on current or previous cohabitation or on divorce were inserted. This means that these Asian surveys can only be used to check whether later ages at parenthood are correlated with the same SDT values indicators as in the West: more egalitarian gender relations, accentuation of non-material benefits in work, stress on autonomy and imagination in educating children, higher post-materialism scores on the Inglehart scales, greater protest-proneness, greater distrust of 
institutions, less weight given to religion, and greater tolerance for breaches in civil and sexual morality.

The data files of the World Values Surveys also had to be pooled for Japan 1995 and 2000, and for South Korea 1994 and 2001 to obtain more than 600 female respondents aged 18-45. For Singapore there was only one survey round. In all countries childlessness was predicted on the basis of age (5 categories), education ( 3 categories: lower secondary, higher secondary, tertiary), occupational status (5 categories: professional, other white collar, blue collar, student, housewife), and one value item per regression. Analysis is conducted using binary logistic regression, and the results for all value items (available on request from the author) are given in the form of exponentiated regression coefficients after controlling for the other covariates. Table 6 indicates the number of such coefficients with net effects on childlessness in the expected direction. For instance, in Japan, 15 of the 16 items related to gender issues had the expected net effect (conformist for earlier parenthood, non-conformist for later parenthood).

Table 6 shows that not all items were present in the surveys of the three countries: Japan contributed 70 items, Korea only 56. The tallies of coefficients for all three countries show that more than 80 percent of them are in the expected direction, indicating an overwhelming concordance with what is found in the West (cf. Surkyn and Lesthaeghe 2004): non-conformist or more libertarian attitudes correctly predict postponement of parenthood. The only exception encountered in these analyses pertains to the religion and secularization items in Japan. Here only four of the ten items are in the expected direction.

I conclude that individual-level data from three advanced Asian economies demonstrate that the demographic dimension of postponement of par-

TABLE 6 Link between later parenthood and sets of value orientations: Number of items with net effects in the expected direction, women aged 18-45 (after controls for age, education, and occupational status)

\begin{tabular}{llll}
\hline & $\begin{array}{l}\text { Japan } \\
\mathbf{1 9 9 5 , 2 0 0 0}\end{array}$ & $\begin{array}{l}\text { South Korea } \\
\mathbf{1 9 9 4 , 2 0 0 1}\end{array}$ & $\begin{array}{l}\text { Singapore } \\
\mathbf{2 0 0 2}\end{array}$ \\
\hline Family and gender items & 15 of 16 & 15 of 16 & 13 of 16 \\
Socialization traits & 7 of 9 & 9 of 9 & 7 of 9 \\
Work characteristics & 5 of 5 & na & 9 of 10 \\
Political orientation & 19 of 20 & 17 of 19 & 7 of 9 \\
Ethics and morality issues & 8 of 10 & 7 of 9 & 9 of 9 \\
Religion and secularization & 4 of 10 & 2 of 3 & 9 of 10 \\
Total & 58 of 70 & 50 of 56 & 54 of 63 \\
Total percent & 83 & 89 & 86 \\
\hline
\end{tabular}

SOURCE: Computed by the author from World Values Surveys Data Files, ISR Michigan. 
enthood can be linked to the same value orientations as those associated with the SDT in Europe. Further checks and stronger evidence would be welcome, and for a start this requires the insertion of simple questions concerning prior cohabitation and divorce along with the question on current marital status. This minor alteration of the World Values Surveys questionnaire and other surveys would make a considerable contribution to further empirical work pertaining to the Asian patterns indicative of the second demographic transition.

\section{Discussion}

Before answering the questions posed at the onset, I make a preliminary point in order to avoid subsequent misunderstanding about the role of culture in the second demographic transition. The SDT theory fully recognizes the effects of macro-level structural changes and of micro-level economic calculus. But it does not consider these explanations as sufficient, but merely as necessary or non-redundant. By the same token, cultural explanations are necessary but not sufficient. Also, the SDT theory does not consider cultural change as endogenous to any economic model, but as a necessary additional force with its own exogenous effects on demographic outcomes. Culture is treated as a dynamic set of value orientations. These orientations can change at the individual level, and they can be linked recursively to the unfolding of the life course. They can also change at the collective level during particular periods of time, or shift to new configurations with the succession of cohorts. The Maslowian drift to higher-order needs is positively related to economic growth, but other factors reflecting historical path dependency (often in religious and political spheres) modulate this connection.

With these remarks in mind, I now turn to the questions posed in the introduction.

\section{Is the SDT merely a continuation of the first transition?}

The second demographic transition differs significantly from the first transition both in terms of demographic predictions and in terms of underlying motivations. Because the SDT predicts generalized sub-replacement fertility in tandem with a greater plurality of living arrangements and household structures, it also points to the growing importance of international migration. Furthermore, the SDT predictions depart from the benign equilibrium outcomes of the first transition, such as a stationary population, not much need for migration, and the predominance of the stable conjugal family. By contrast, sustained subreplacement fertility will accelerate population aging and put a strain on welfare systems. Such low fertility will also stimulate replacement migration as a means of countering labor force shortages. In addition, some of the new living arrangements may be more unstable than traditional arrangements, or may be 
less adequate as a setting for procreation and socialization. Union dissolution will remain a major cause of low fertility as well.

\section{Did the SDT spread beyond Northern and Western Europe?}

Here, the answer is definitely affirmative. The SDT did not stop at the Pyrenees or Alps, but crossed into Central and Eastern Europe as well. All of these areas witnessed a rise in the share of extramarital births, which clearly points in the direction of new contexts of procreation, such as cohabitation and single parenthood. Equally striking is the finding that the individual value profiles according to living arrangement were similar across all parts of Europe.

Were the demographic changes since 1990 in Central and Eastern Europe mainly the outcome of transition to a market economy?

The economic crisis of the early 1990s in Eastern and Central Europe was propitious for the postponement of marriages and births, and hence for the dip to very low levels of fertility. But a purely crisis-based explanation is untenable. First, much of the crisis has long since ended in countries such as Slovenia, the Czech Republic, and Hungary, where GDP per capita has risen to levels higher than in the 1980s, yet we have seen no return to earlier age at marriage or higher fertility. Instead, cohabitation and procreation outside marriage are spreading. Second, the SDT seems to advance faster in countries with more successful economic and political performance, which is again indicative of the importance of factors other than those associated with the economic crisis. Major structural and cultural factors promoted the sustained diffusion of the SDT. On the structural side, for instance, the post-Communist era has been characterized by expanding female education in several of these countries, and this has definitely contributed to the postponement of marriages and births (e.g., Kantorova 2004). Similarly, the rise of individual autonomy and freedom of choice has legitimized the adoption of nontraditional living arrangements in a very short time. These features will not be reversed easily, hence the SDT in Central and Eastern Europe will continue on its course as in Western and Northern Europe.

Are the various demographic ingredients of the SDT performing as a cohesive whole?

Multiple variants of the SDT have emerged. At one end of the scale, Northern and Western European populations experienced early development of 
nonconventional household formation patterns and early emergence of parenthood postponement, but they have maintained higher levels of subreplacement fertility as recuperation at later ages of first and second births was substantial. At the other end are later "postponers" but with much weaker recuperation in overall fertility, and hence a pattern of lowest-low fertility in its third decade. Similarly, both the timing and the spatial patterns of cohabitation and fertility postponement can be disjunct. Time lags between these two aspects of the SDT vary widely, and spatial correspondence between them can be weak or absent. Finally, the values associated with the SDT represent a cohesive package when it comes to their effects on parenthood postponement, but not where recuperation is concerned. In fact, at a later stage in the life cycle, greater gender symmetry and more developed services aimed at reducing opportunity costs of childbearing to working women seem to be linked to greater recuperation of fertility and consequently to higher levels of period fertility.

\section{Can the SDT spread to other continents and non-European societies?}

It has clearly been shown that the SDT can spread beyond Western societies. At this point it appears that several advanced Asian populations have joined the set of SDT countries, since all characteristics except one (procreation among cohabitants) have emerged. Moreover, the micro-level data for Japan, South Korea, and Singapore are consistent with value orientations commonly found in European countries.

Admittedly it will remain difficult to separate the effects of structural factors and ideational factors on marriage postponement and low fertility. Nevertheless, it is widely acknowledged that mass media are producing a "world culture" in which individual autonomy and self-actualization have a prominent, if not dominant place, and that these provide both motivations and justifications for the onset of the SDT. Political, religious, and ideological backlashes are of course always possible (e.g., Christian and Muslim fundamentalist reactions), but to this point such reactions have not been sufficient to cause a decisive retreat from SDT values in countries with democratic governance.

Several decades of experience in countries as distinct from each other as Sweden and Japan have revealed the diversity of SDT development paths and the existence of historical and cultural reasons for such heterogeneity. But despite such distinctions, an important set of SDT predictions still holds:

1) The normative and institutional bases of traditional union formation and household structure will systematically weaken in all societies that adopt egalitarian and democratic systems governed by respect for individual choice. This prediction implies that other forms of union formation will ex- 
pand in the wake of such ideational developments. The political evolution of countries is thus at least as crucial for the onset of the SDT as their economic circumstances.

2) Alongside individual autonomy, self-realization will become a major goal in its own right. This will produce a rising demand for higher education, especially among women, stimulate other tastes and life styles, and result in sub-replacement fertility.

3) Communication technology and mass media are spreading knowledge about new forms of behavior to all corners of the world. Moreover, new forms of behavior are associated by the public itself with being "more advanced" and "more developed" (Thornton 2005). Just as the first demographic transition in many developing countries benefited from this communication revolution, so will the diffusion of the second transition be enhanced by global communication and by the power of what Thornton calls "developmental idealism."

4) Fundamentalist reactions are likely to occur in response to these global ideational shifts, but so far their success has been too limited to stem the overall shift toward post-materialist and expressive value orientations. In short, such reactions might slow the diffusion of the SDT or produce marked spatial differences, but they cannot stem the tide altogether. 
APPENDIX TABLE 1 Overview of demographic and societal characteristics related to the first and second demographic transitions in Western Europe

First transition

\section{Marriage}

Rise in proportions marrying, declining age at first marriage

Low or reduced cohabitation

Low divorce

High remarriage

\section{Fertility}

Decline in marital fertility via reductions at older ages, lowering mean ages at childbearing

Deficient contraception, parity failures

Declining illegitimate fertility, but not necessarily among teenage women

Low definitive childlessness among married couples

\section{Societal background}

Preoccupations with basic material needs: income, work conditions, housing, health, schooling, social security; solidarity is prime value

Rising memberships in political, civic, and community-oriented networks; strengthening of social cohesion

Strong normative regulation by Church and State; first secularization wave, dominance of political and social factions ("pillars")

Segregated gender roles, familistic policies, embourgeoisement, promotion of breadwinner family model

Ordered life-course transitions, prudent marriage, and dominance of a single model of the family
Second transition

Fall in proportions married, rise in age at first marriage

Rise in cohabitation (pre- and postmarital)

Rise in divorce, earlier divorce

Decline in remarriage following both divorce and widowhood

Further decline in fertility via postponement, increasing mean age at first parenthood, structural sub-replacement fertility

Efficient contraception (exceptions in specific social groups)

Rising extramarital fertility due to parenthood within cohabitation

Rising definitive childlessness in unions

Rise of higher-order needs: individual autonomy, self-actualization, expressive work and socialization values, grassroots democracy, recognition by others; tolerance is prime value

Disengagement from civic and communityoriented networks, social capital shifts to expressive and affective types; weakening of social cohesion

Retreat of the state, second secularization wave, sexual revolution, refusal of authority, waning influence of political factions ("pillars")

Rising symmetry in gender roles, female economic autonomy

Flexible life-course organization, multiple lifestyles, open future 


\section{Notes}

Figures 1, 6, and 7 in this article are available in color in the electronic edition of the journal.

This essay was first presented at the conference on "Fertility in the History of the 20th Century-Trends, Theories, Public Discourses, and Policies," Academia Leopoldina \& BerlinBrandenburgische Akademie, Berlin, 21-23 January 2010. The author thanks Tomas Frejka and Arland Thornton for comments.

1 It should be noted that most demographers writing during the interbellum forecasted a sustained period of sub-replacement fertility and did not take a stationary population as a transition endpoint (cf. Demeny 1997; Van Bavel 2010). In reality, only a few countries (mainly Germany, Sweden, and England) had a period TFR declining below 2 children for any length of time, and by the end of the 1930s all had rising TFR values. Other countries such as the Netherlands, Canada, and Italy never had TFRs below 2.5 children during the entire interbellum period. In addition, the reason for "sub-replacement fertility" during the 1930s was as much a result of significantly lower probabilities of survival to the mean age of motherhood as it was a matter of lower TFRs. In other words, "sub-replacement fertility" then (first demographic transition) and "sub-replacement fertility" now (second demographic transition) reflect different mortality conditions.

Returning to fertility as such, this clearly crisis-induced first transition fertility drop in the 1930s was not only geographically contained, but also of a much shorter duration than its postwar SDT counterpart, which spans several decades and has not yet come to an end. Also cohort measures of fertility were virtually never used at that time, hence a crisis-induced tempo effect (postponement of first marriages and first births) was misread as a "structural" feature that would lead to shrinking populations. Finally, marriage postponement during the 1930s was unrelated to a rise in cohabitation, hence has nothing in common with the SDT restructuring of living arrangements of couples. In my opinion, the experience of the 1930s can hardly be interpreted as a "dress rehearsal" for the SDT (cf.
Van Bavel 2010, p. 12), but as a period reaction, limited in time, to the shock of severe economic, social, and political crises.

2 The early study by Cliquet (1992) and the much later presentation by Coleman (2004) are to my knowledge the only published cogent critiques of the SDT, and they serve as the guidelines for the present analysis. Various unpublished critiques and comments were voiced during conferences or seminars.

3 A crucial distinction needs to be made between unplanned nonmarital fertility among single young women, often leading to single-mother households, and the often planned nonmarital fertility of older cohabiting couples. The first type is an indicator of an incomplete first demographic transition and is caused by lack of contraceptive knowledge and/or practice. Only the second type is indicative of the SDT.

4 The most recent TFR levels in the United States, Australia, and New Zealand are all very close to replacement level or even above it. This has been taken as evidence by a reviewer that these are not SDT countries or that the SDT theory simply does not hold. This critique overlooks the heterogeneous population composition and the presence of subpopulations that have not yet completed their demographic transition. In the US, the Hispanic TFR was still 3.0 in 2007, whereas that of non-Hispanic whites was 1.9 (including in this average the high fertility of Mormons and Evangelicals), setting the national level at 2.1 (National Vital Statistics Report, March 2009). The high US teenage fertility level (which is rising among Hispanics) is also indicative of an incomplete transition. Similarly, in New Zealand the national TFR was above replacement in 2006 only because of the Maori TFR of 2.8, and despite the low fertility of the New Zealand Asians (TFR=1.5). In Australia, the TFR rose rapidly from 1.8 in 2005 to 2.0 in 2008. Here the Aborigines' contribution was negligible, but a large birth premium of \$A 5,000 (about US $\$ 4,500$ ) has probably spurred the recuperation of births after 2004. But since one can have a second child only once, the effect of this bonus is expected to wear off (cf. 
the temporary effect of the prolongation of Sweden's maternity leave).

5 All these effects are net effects, established after controls for the typical structural background variables such as age, education, place of residence, income or socioeconomic status, and employment status.

6 Sobotka used attitudinal items from the 1999-2000 EVS to identify SDT values. His SDT values index contains eight items pertaining to gender equity, secularization, sense of freedom of choice, importance of children and leisure, marriage as an institution, and ethics (see Sobotka 2008: 85-86). Lesthaeghe and Surkyn (2002) and Surkyn and Lesthaeghe (2004) used a much larger set of 80 items from the same source to map the unfolding differentiations in life-course patterns in European countries.

7 Most Western and Northern European countries benefit from the higher fertility of their mainly Muslim subpopulations. Their contribution to national TFRs is commonly on the order of 0.10 births (Sobotka 2008: 56). For example, if a subpopulation of 10 percent of the total contributes a TFR of 2.8 , and the remaining 90 percent has a sub-replacement TFR of 1.8, then the overall TFR is 1.9.

8 At this point one may speculate about whether China is experiencing the second demographic transition. Because of China's large size, certain subpopulations may move into the SDT well ahead of others. Hence the question cannot be answered for the Chinese population as a whole. Second, the country's currently very low TFR is in part a product of the one-child policy. Detecting the SDT effect would require that the one-child policy be lifted. Only then could it be seen where fertility rebounds to or above replacement level and where it does not. Finally, rises both in mean ages at marriage and in premarital cohabitation would be needed to make the case that Chinese subpopulations have joined the SDT group.

\section{References}

Alwin, D. 1989. "Changes in qualities valued in children, 1964-1984," Social Science Research 44(2): 1-42.

Ariès, P. 1962. Centuries of Childhood-A Social History of Family Life. New York: Random House.

. 1980. "Two successive motivations for the declining birth rates in the West," in C. Höhn and R. Mackensen (eds.), Determinants of Fertility Trends-Theories Re-examined. Liège: IUSSP Bad Homburg Conference Proceedings, pp. 125-130. Also in Population and Development Review 6(4): 645-650.

Axinn, W. G. and A. Thornton. 1993. "Mothers, children, and cohabitation: The intergenerational effects of attitudes and behavior," American Sociological Review 58(2): 233-246.

Barber, J. 2001. "Ideational influences on the transition to parenthood: Attitudes toward childbearing and competing alternatives," Social Psychology Quarterly 4: 101-127.

Billari, F. C. and H-P. Kohler. 2004. "Patterns of low and very low fertility in Europe," Population Studies 58(2): 389-402.

Bongaarts, J. and G. Feeney. 1998. "On the quantum and tempo of fertility," Population and Development Review 24(2): 271-291.

Clarkberg, M. 2002. "Family formation experiences and changing values: The effects of cohabitation and marriage on the important things in life," in R. Lesthaeghe (ed.), Meaning and Choice: Value Orientations and Life Course Decisions. The Hague: Netherlands Interdisciplinary Demographic Institute, pp.183-250.

Cliquet, R. 1992. "The second demographic transition: Fact or fiction?," Council of Europe Population Studies 23. Strasbourg: Council of Europe.

Coleman, D. 2004. "Why we don't have to believe without doubting in the 'Second Demographic Transition'-Some agnostic comments," Vienna Yearbook of Population Research, 2004, pp. 11-24. 
Council of Europe. 2004. Recent Demographic Developments in Europe, 2003. Strasbourg: Council of Europe Publishing, pp. 66-68.

Dalla Zuanna, G. 2002. “The banquet of Aeolus: A familistic interpretation of Italy's lowest-low fertility," Demographic Research 4(5): 133-161. See also online at "www.demographicresearch.org".

Demeny, P. 1997. “Replacement-level fertility: The implausible endpoint of the demographic transition," in G. W. Jones et al. (eds.), The Continuing Demographic Transition. Oxford: Clarendon Press, pp. 94-110.

Easterlin, R. A. 1973. "Relative economic status and the American fertility swing." in E. Sheldon (ed.), Family Economic Behavior. Philadelphia: Lippincott, pp. 170-223.

Frejka, T. and G. Calot. 2001. "Cohort reproductive patterns in low-fertility countries," Population and Development Review 27(1): 103-132.

Frejka, T. and J-P. Sardon. 2004. Childbearing Trends and Prospects in Low-Fertility Countries. Dordrecht: Kluwer Academic Publishers. . 2009. "Contemporary childbearing trends in low-fertility countries," paper presented at the 26th IUSSP International Population Conference, Marrakesh, 27 September-2 October.

Goode, W. J. 1963. World Revolution and Family Patterns. New York: The Free Press; London: Collier-Macmillan.

Guerrero, L. 1995. “The Filipino family, gender roles and other women's issues: The 1994 ISSP Survey," Social Weather Stations Occasional Paper, Diliman, Quezon City.

Inglehart, R. 1970. The Silent Revolution. Princeton: Princeton University Press. - 1990. Culture Shift in Advanced Industrial Society. Princeton: Princeton University Press. . 1997. Modernization and Postmodernization-Cultural, Economic and Political Change in 43 Societies. Princeton: Princeton University Press.

Jansen, M. and M. Kalmijn. 2002. "Investment in family life: The impact of value orientations on patterns of consumption, production and reproduction in married and cohabiting couples," in R. Lesthaeghe (ed.), Meaning and Choice: Value Orientations and Life Course Decisions. The Hague: Netherlands Interdisciplinary Demographic Institute, pp. 129-159.

Jones, G. W. 2004. "Not when to marry but whether to marry: The changing context of marriage decisions in East and South-East Asia," in G. W. Jones and K. Ramdas (eds.), Untying the Knot: Ideal and Reality in Asian Marriage. Singapore: Asian Research Institute, National University of Singapore.

- 2005. "The flight from marriage in South-East and East Asia," Journal of Comparative Family Studies 36(1): 93-1 19.

Jones, G. W., P. T. Straughan, and A. Chan (eds.). 2009. Ultra-low Fertility in Pacific Asia: Trends, Causes and Policy Issues. London and New York: Routledge, Taylor and Francis Group.

Kantorova, V. 2004. "Education and entry into motherhood-The Czech Republic during state socialism and the transition period, 1970-1997," Demographic Review S3, paper 10 (see also online special collection S3-10).

Kiernan, K. 2001. Discussant's comment at European Science Foundation Seminar on the Second Demographic Transition, Bad Herrenalb, 23-28 June.

Kohler, H-P., F. C. Billari, and J. A. Ortega. 2002. "The emergence of lowest-low fertility in Europe during the 1990s," Population and Development Review 28(4): 641-680.

Kohn, M. L. 1977. Class and Conformity. A Study in Values. Chicago: University of Chicago Press.

Lesthaeghe, R. 2001. "Postponement and recuperation-Recent fertility trends and forecasts in six Western European countries," paper presented at the IUSSP seminar on below replacement fertility, Tokyo, 21-23 March.

- (ed.). 2002. Meaning and Choice: Value Orientations and Life Course Decisions. The Hague: Netherlands Interdisciplinary Demographic Institute.

. 2009. "Long term spatial continuities in demographic innovations-Insights from the Belgian example, 1846-2000," paper presented at the Seminar on Historical Continuities 
in Demographic Patterns, Max Planck Institute for Demographic Research, Rostock, 25-27 May, unpublished.

Lesthaeghe, R. and G. Moors. 1995. “Living arrangements, socio-economic positions and values among young adults: A pattern description for France, Germany, Belgium and the Netherlands, 1981-1990," in D. Coleman (ed.), Europe's Population in the 1990s. Oxford: Oxford University Press, Chapter 6.

Lesthaeghe, R. and L. Neidert. 2006. "The second demographic transition in the United States: Exception or textbook example?," Population and Development Review 32 (4): 669-698.

Lesthaeghe, R. and J. R. Surkyn. 2002. "New forms of household formation in Central and Eastern Europe: Are they related to newly emerging value orientations?," UNECE Economic Survey of Europe, 2002-1, Chapter 6. Geneva: United Nations Commission for Europe, pp. 197-216.

Lesthaeghe, R. and D. J. van de Kaa. 1986. “Twee Demografische Transities?," in R. Lesthaeghe and D. J. van de Kaa (eds.), Bevolking: Groei en Krimp. Mens en Maatschappij book supplement. Deventer: Van Loghum-Slaterus, pp. 9-24.

Lesthaeghe, R. and P. Willems. 1999. "Is low fertility a temporary phenomenon in the European Union?," Population and Development Review 25(2): 211-228.

Livi-Bacci, M. 1971. A Century of Portuguese Fertility. Princeton: Princeton University Press.

Maslow, A. 1954. Motivation and Personality. New York: Harper and Row.

Matsuo, H. 2001. "Is Japan a second demographic transition country?," European Science Foundation Seminar on the Second Demographic Transition, Bad Herrenalb, 23-28 June.

Micheli, G. A. 1996. “New patterns of family formation in Italy: Which tools for which interpretation?," Genus 52(1-2): 15-52.

- 2000. "Kinship, family and social network: The anthropological embedment of fertility change in Southern Europe," Demographic Research 3(13).

Moors, G. 1997. "The dynamics of values-based selection and values adaptation." Brussels: Vrije Universiteit Brussel, Ph.D. dissertation in sociology.

Neels, K. 2006. Reproductive Strategies in Belgian Fertility. The Hague: Netherlands Interdisciplinary Demographic Institute.

- 2009. "Postponement and recuperation of cohort fertility," paper presented at the 26th IUSSP International Population Conference, Marrakesh, 27 September - 2 October.

Palomba, R. 1995. "Italy: The invisible change," in R. Palomba and H. Moors (eds.), Population, Family and Welfare. Oxford: Clarendon Press, pp. 158-176.

Prioux, F. 2008. “L'évolution démographique en France: L'éspérance de vie progresse toujours," Population 63(3): 464.

Putnam, R. 2000. Bowling Alone. New York: Simon and Schuster.

Rabusic, L. 2001. "Value change and demographic behaviour in the Czech Republic," Czech Sociological Review 9(1): 99-122.

Raymo, J., M. Iwasawa, and L. Bumpass. 2008. “Cohabitation and family formation in Japan," Osaka University, Graduate School of Economics, GCOE Discussion Paper no. 3.

Reher, D. S. 1998. "Family ties in Western Europe: Persistent contrasts," Population and Development Review 24(2): 203-234.

Sobotka, T. 2002. "Ten years of rapid fertility changes in European post-Communist countries-Evidence and interpretation," Groningen Population Research Center Working Papers, no. 2002-1. Groningen NL: University of Groningen.

_. 2004. "Is lowest-low fertility explained by the postponement of childbearing?," Population and Development Review 30(2): 195-220.

- 2008. "Does persistent low fertility threaten the future of European populations?," in J. Surkyn et al. (eds.), Demographic Challenges for the 21 st Century. Brussels: VUBPress, pp. 27-90.

Sowers, E. and R. Lesthaeghe. 2008. "Sub-replacement fertility models: Why pure postponement models are inadequate," poster presented at the Annual Meeting of the Population Association of America, New Orleans «http: //webfiles.uci.edu/esowers/www/». 
Surkyn, J. and R. Lesthaeghe 2004. "Values orientations and the second demographic transition (SDT) in Northern, Western and Southern Europe: An update," Demographic Research S3(3). Rostock: Max Planck Institute for Demographic Research. See online at "Www. demographic-research.org ". See also J. R. Surkyn and R. Lesthaeghe (2004), "Wertorientierungen und die 'Second Demographic Transition' in Nord-, West- und Südeuropa: Ein aktuelle Bestandsaufnahme," Zeitschrift für Bevölkerungswissenschaft 1: 63-98.

Thévenon, O. 2009. "L'augmentation de l'activité des femmes en Europe: Progrès de la conciliation ou polarization des comportements?," Population 64(2): 263-304.

Thornton, A. 1985. "Reciprocal influences of family and religion in a changing world," Journal of Marriage and the Family 47: 381-394.

- 2005. Reading History Sideways: The Fallacy and Enduring Impact of the Developmental Paradigm on Family Life. Chicago: University of Chicago Press.

Thornton, A., W. G. Axinn, and D. Hill. 1992. "Reciprocal effects of religiosity, cohabitation and marriage," American Journal of Sociology 98: 628-651.

Tsuya, N. 2006. "Patterns and covariates of partnership formation in Japan," Journal of Population Problems (Jinko Mondai Kenkyu) 62(1-2): 1-19.

- 2009. "Will the second demographic transition be global? The case of Japan," presentation at Forum Discussion 215, 26th IUSSP International Population Conference, Marrakesh, 27 September-2 October.

Tu, E. J. C. and X. Zhang. 2004. "Patterns of low fertility in Hong Kong and Taiwan," Hong Kong University of Science and Technology, Social Science Division, Knowloon, unpublished paper.

UN Economic Commission for Europe (UNECE). 1999. “Fertility decline in transition economies, 1982-1997: Political, economic and social factors," Economic Survey of Europe 1999 1: 181-194.

- 2000. "Fertility decline in transition economies, 1989-1998: Economic and social factors revisited," Economic Survey of Europe 2000 1: 189-207.

Van Bavel, J. 2010. "Subreplacement fertility in the West before the baby boom: Past and current perspectives," Population Studies 64(1): 1-18.

van de Kaa, D. J. 2002. "The idea of a second demographic transition in industrialized countries," Paper 6th Welfare Policy Seminar, National Institute of Population and Social Security, Tokyo, 29 January.

- 2004. "The true commonality: In reflexive modern societies fertility is a derivative," Population Studies 58(1): 77-81.

van Rijsselt, R. 1989. "Developments in attitudes and values orientations: A comparison between birth cohorts in the Netherlands over the period 1970-1985," Symposium on Life Histories and Generations, Netherlands Institute for Advanced Studies (NIAS), Wassenaar, 22-23 June.

Waite, L. J. , F. K. Goldscheider, and C. Witsberger. 1986. "Nonfamily living and the erosion of traditional family orientations among young adults," American Sociological Review 51: 541-554.

Zakharov, S. 1997. "Fertility trends in Russia and the European new independent states: Crisis or turning point?," Expert Group Meeting on Below-replacement Fertility, ESA/ P/WP.140, 4-6 November. New York: United Nations Population Division.

Zakharov, S. and E. Ivanova. 1996. "Fertility decline and recent changes in Russia-On the threshold of the second demographic transition," in J. DaVanzo (ed.), Russia's Demographic Crisis. Santa Monica: RAND, pp. 36-82.

Zeman, K., T. Sobotka, and V. Kantorova. 2001. "Halfway between socialist greenhouse and postmodern plurality: Life course transitions of young Czech women," paper presented at the European Science Foundation Seminar on the Second Demographic Transition, Bad Herrenalb, 23-28 June.

Zhang, X. 2005. "Postponement of childbearing and lowest-low fertility, Hong Kong 19762001," Powerpoint slides, Hong Kong University of Science and Technology, Social Science Division. 